\title{
The role of vitamins in the prevention and control of anaemia
}

\author{
Steven M Fishman, Parul Christian* and Keith P West Jr \\ Division of Human Nutrition, Johns Hopkins School of Hygiene and Public Health, Baltimore, MD 21205 , USA
}

Submitted 23 September 1999: Accepted 12 January 2000

\begin{abstract}
Objective: While iron deficiency is regarded as the major cause of nutritional anaemia, changes in vitamins $\mathrm{A}, \mathrm{B}_{12}, \mathrm{C}$ and $\mathrm{E}$, folic acid and riboflavin status have also been linked to its development and control. This paper provides a systematic review of vitamin supplementation trials relating to the control of nutritional anaemia.

Methods: A MEDLINE search was used to find reports of vitamin supplementation trials that reported changes in anaemia or iron status.

Results: Vitamin A can improve haematological indicators and enhance the efficacy of iron supplementation. Both folate and vitamin $\mathrm{B}_{12}$ can cure and prevent megaloblastic anaemia. Riboflavin enhances the haematological response to iron, and its deficiency may account for a significant proportion of anaemia in many populations. Vitamin $\mathrm{C}$ enhances the absorption of dietary iron, although population-based data showing its efficacy in reducing anaemia or iron deficiency are lacking. Vitamin E supplementation given to preterm infants has not reduced the severity of the anaemia of prematurity. Vitamin $\mathrm{B}_{6}$ effectively treats sideroblastic anaemia. Multivitamin supplementation may raise haemoglobin ( $\mathrm{Hb}$ ) concentration, but few studies have isolated the effect of multivitamins from iron on haematological status.

Conclusions: In general, the public health impact of vitamin supplementation in controlling anaemia is not clear. Neither are the complex interactions involving multiple vitamins in haematopoiesis sufficiently understood to explain the observed variability in haematological responses to vitamins by age, population, vitamin mixture and dosages. Further research is needed to understand the roles of individual and combined vitamin deficiencies on anaemia to design appropriate micronutrient interventions to prevent anaemia.
\end{abstract}

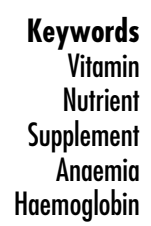

Controlled trials provide evidence that adequate iron supplementation improves iron status and prevents anaemia, but there are various physiological, economic, social and logistical obstacles to achieving its effectiveness in practice $^{5}$. The maintenance of normal haematopoietic function also requires adequate levels of many other nutrients acting in concert. While deficiencies of such 'accessory' nutrients may occur in isolation, they usually exist in combination. Unfortunately, the roles and mechanisms by which many nutrients influence the pathogenesis or prevention of anaemia remain obscure. Figure 1 illustrates some of the basic features of iron metabolism and erythropoiesis, emphasizing points in the process at which certain vitamins may influence iron deficiency and anaemia. Vitamins such as vitamin A, folic acid, vitamin $\mathrm{B}_{12}$, riboflavin and vitamin $\mathrm{B}_{6}$, are necessary for the normal production of red blood cells, while others such as vitamins $\mathrm{C}$ and $\mathrm{E}$ protect mature red blood cells from premature destruction by free radical oxidation (Table 2 ). Riboflavin, vitamin A and vitamin $\mathrm{C}$ may also prevent anaemia by improving intestinal absorption of iron, or by facilitating its mobilization from body stores. This paper explores the effects of these vitamins in the treatment and 
Table 1 Haemoglobin and haematocrit cut-offs used to define anaemia among different population groups. (From WHO/UNICEF/ $\mathrm{UNU}^{2}$ )

\begin{tabular}{lcc}
\hline Group & $\begin{array}{c}\text { Haemoglobin } \\
\text { below }\end{array}$ & $\begin{array}{c}\text { Haematocrit } \\
\text { below }\end{array}$ \\
\hline Children 6 months to 5 years & $110 \mathrm{gl}^{-1}$ & 0.33 \\
Children 5-11 years & $115 \mathrm{gl}^{-1}$ & 0.34 \\
Children 12-13 years & $120 \mathrm{gl}^{-1}$ & 0.36 \\
Non-pregnant women & $120 \mathrm{gl}^{-1}$ & 0.36 \\
Pregnant women & $110 \mathrm{gl}^{-1}$ & 0.33 \\
Men & $130 \mathrm{gl}^{-1}$ & 0.39 \\
\hline
\end{tabular}

prevention of anaemia in human populations and identifies areas for future research.

\section{Methods}

Controlled vitamin supplementation and fortification trials that reported changes in anaemia (by Hb or Hct indicators) or iron status were considered for review. Studies were identified, first, by a MEDLINE search using combinations of the following keywords: vitamin, multivitamin, nutrient, anaemia, haemoglobin, iron deficiency and supplement. This was followed by a search of references cited by relevant studies, and a search of recent editions of nonMEDLINE nutrition journals. The search focused primarily on English-language human studies published since 1967,
Table 2 Mechanisms by which vitamin deficiencies can play roles in the development of anaemia

\begin{tabular}{|c|c|}
\hline Vitamin deficiency & Possible role in anaemia through: \\
\hline Vitamin A & $\begin{array}{l}\text { Impaired mobilization of iron stores } \\
\text { Impaired erythropoiesis } \\
\text { Increased susceptibility to infection }\end{array}$ \\
\hline Folic acid & $\begin{array}{l}\text { Impaired DNA synthesis, leading to ineffective } \\
\text { erythropoiesis }\end{array}$ \\
\hline Vitamin $B_{12}$ & $\begin{array}{l}\text { Impaired metabolism of folate, leading to } \\
\text { ineffective erythropoiesis }\end{array}$ \\
\hline Riboflavin & $\begin{array}{l}\text { Impaired iron mobilization } \\
\text { Impaired globin production, leading to } \\
\text { impaired erythropoiesis } \\
\text { Reduced intestinal absorptive capacity }\end{array}$ \\
\hline Vitamin C & $\begin{array}{l}\text { Reduced absorption of iron } \\
\text { Reduced mobilization of iron from stores } \\
\text { Impaired folate metabolism } \\
\text { Oxidant damage to erythrocytes, leading to } \\
\text { haemolysis } \\
\text { Capillary haemorrhaging, leading to blood loss }\end{array}$ \\
\hline Vitamin $\mathrm{E}$ & $\begin{array}{l}\text { Oxidant damage to erythrocytes, leading to } \\
\text { haemolysis }\end{array}$ \\
\hline Vitamin $\mathrm{B}_{6}$ & $\begin{array}{l}\text { Impaired haem synthesis, leading to impaired } \\
\text { erythropoiesis }\end{array}$ \\
\hline
\end{tabular}

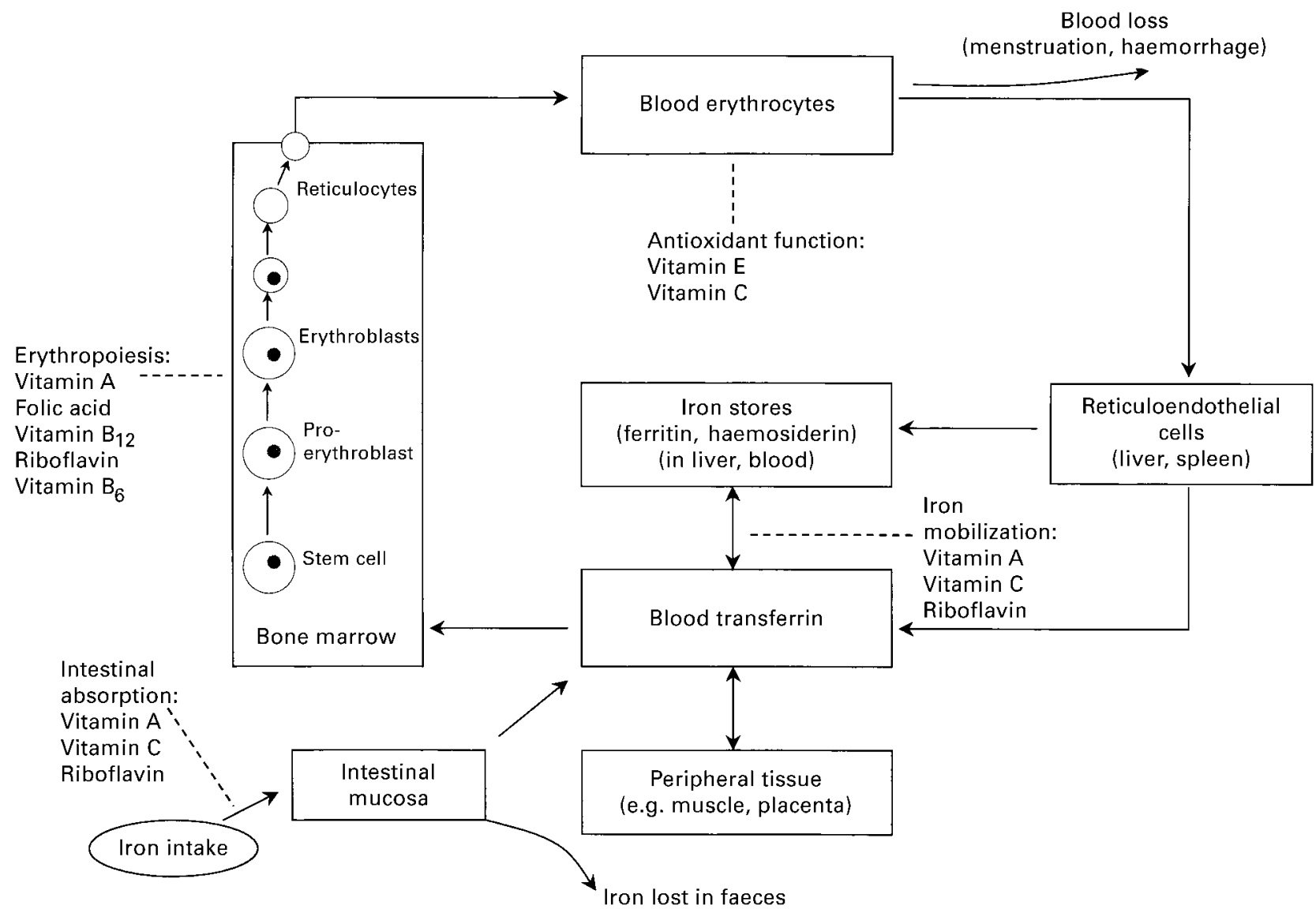

Fig. 1 Vitamin roles in iron metabolism and erythropoiesis. (Adapted from Hughes-Jones \& Wickramasinghe ${ }^{57}$ ) 
although a number of seminal early papers are cited to provide historical perspective.

\section{Vitamin A}

An estimated 190-255 million preschool-aged children throughout the world are vitamin A deficient, with some 3-5 million having xerophthalmia, and 500000 becoming blind and dying each year ${ }^{11-14}$. Vitamin A deficiency may be responsible for $25-35 \%$ of all early childhood deaths in high risk regions of the developing world, attributed to increased severity of infection in a deficient state ${ }^{15-17}$.

There appears to be a causal relationship between vitamin A deficiency and anaemia. Early studies of vitamin A-deficient rats reported haematological disturbances such as losses of haematopoietic tissue in bone marrow, hypochromia, depressed $\mathrm{Hb}$ concentration and splenic accumulation of haemosiderin. Interpretation of these effects was complicated by results from other studies showing that initial declines in $\mathrm{Hb}$ levels and erythrocyte counts were followed by increases in packed cell volumes and $\mathrm{Hb}$ levels as deficiency progressed, creating apparent polycythaemia rather than anaemia ${ }^{18-21}$. The increase in blood $\mathrm{Hb}$ level seen in some studies has been attributed to haemoconcentration resulting from dehydration and diarrhoea associated with severe vitamin A deficiency ${ }^{20}$. Restoration of vitamin A to the diet of deficient animals was followed by regeneration of the bone marrow, disappearance of haemosiderin from the spleen and liver, and enhanced erythroblastic activity ${ }^{22}$.

In humans, cross-sectional studies show positive correlations between serum retinol concentration and $\mathrm{Hb}$ that are more apparent with poorer vitamin A status and possibly age, at least in children. Chronically mild to moderately vitamin A-deficient children are more likely to be anaemic than their non-deficient peers ${ }^{13}$. Six Central American nutrition surveys and biochemical studies in Ethiopia and Bangladesh observed modest, positive correlations between circulating retinol and $\mathrm{Hb}$ levels in children ( $r$ c.0.21), suggesting that serum retinol accounts for $4-10 \%$ of the variation in $\mathrm{Hb}$ concentration ${ }^{23-25}$. The correlation was slightly stronger among severely vitamin A-deficient school-aged children $(r \text { c.0.31 })^{23}$. A weaker relationship was observed in Central American children aged 1-4 years $(r c .0 .13, P>0.05)^{23}$. Although no association was observed among 1-8-year-old hyporetinolaemic Thai children ${ }^{26}$, a strong correlation ( $\left.r c .0 .52\right)$ between $\mathrm{Hb}$ and plasma retinol concentration was observed among anaemic $\left(\mathrm{Hb}<110 \mathrm{gl}^{-1}\right)$, malnourished school-aged Indian children $^{27}$. An even stronger mean correlation (overall $r=$ 0.78 ) between $\mathrm{Hb}$ and plasma retinol was reported from nutritional surveys of non-pregnant, non-lactating women of reproductive age in eight developing countries ${ }^{28}$. Intervention trials among women, however, suggest a more complex relationship (see below).

Positive haematological responses to vitamin A, most consistently reflected in increased $\mathrm{Hb}$ and serum iron concentrations, have been observed among children and pregnant women, whether the vitamin A was delivered as a regular supplement, a single dose or a fortified food item. Mejia and Arroyave found that 6 months after the start of a vitamin A sugar-fortification programme that provided approximately 330-360 $\mu \mathrm{g}$ retinol equivalents (RE) per child per day, serum iron levels of preschool children had increased $\left(+0.81 \mu \mathrm{mol}^{-1}\right)$ and serum ferritin concentrations had declined $\left(-3.0 \mu \mathrm{gl}^{-1}\right)$, suggesting that existing body iron stores were mobilized to increase iron availability to tissues ${ }^{29}$. After 18 and 24 months, serum iron, transferrin saturation and serum ferritin were higher than baseline levels ${ }^{29,30}$. While strongly suggestive of a vitamin A response, there was no comparison group against which these changes could be judged, and $\mathrm{Hb}$ concentrations were not measured.

Vitamin A trials employing concurrent comparison groups to evaluate impact on anaemia are summarized in Table 3. Among Indonesian preschoolers, consuming c. $240 \mu \mathrm{g} R$ day $^{-1}$ from vitamin A-fortified monosodium glutamate (MSG) for 5 months significantly increased Hb concentration by $c .10 \mathrm{gl}^{-1}$, while $\mathrm{Hb}$ concentrations in a concurrent control group remained about the same $\left(-2 \mathrm{gl}^{-1}\right)^{31}$. Hb did not increase further after six additional months of vitamin A-fortified MSG intake despite continued improvement in vitamin A status, suggesting that dietary iron, or possibly other anaemia prevention measures, may have been required to further improve $\mathrm{Hb}$ concentration ${ }^{13,31}$.

Mejia and Chew studied the effect of supplementing anaemic Guatemalan children aged 1-8 years daily with vitamin A (1500-3000 $\mu \mathrm{g} \mathrm{RE})$ or iron $\left(3 \mathrm{mg} \mathrm{kg}^{-1}\right)$ for 2 months ${ }^{32}$. Supplementation with vitamin A alone elevated the concentration of serum iron by $2 \mu \mathrm{moll}^{-1}$, transferrin saturation by $3 \%$, and $\mathrm{Hb}$ by $9 \mathrm{gl}^{-1}$ but had no effect on serum ferritin (i.e. apparent iron stores). Vitamin A plus iron produced positive gains in $\mathrm{Hb}\left(14 \mathrm{gl}^{-1}\right)$ and ferritin $\left(5 \mu \mathrm{gl}^{-1}\right)$, but these increments were similar to the responses observed with iron alone. Vitamin A and iron combined, however, increased transferrin saturation (by another $c .5 \%$ ) and serum iron (by another $4 \mu \mathrm{moll}^{-1}$ ) more than either supplement alone. The findings suggest that adequate vitamin A status can help maintain adequacy of plasma iron to supply body tissues, including bone marrow, which may in turn enhance haematopoiesis ${ }^{32}$. Supporting this inference are the significant increases in $\mathrm{Hb}$ $\left(+6 \mathrm{gl}^{-1}\right)$, Hct $(+0.02)$ and plasma iron $\left(+2.33 \mu \mathrm{moll}^{-1}\right)$ reported among xerophthalmic Indian children aged 4-12 years ${ }^{27}$ who were given $8 \mathrm{mg}$ of retinyl palmitate daily for 2-3 weeks and the improved $\mathrm{Hb}$ concentrations following weekly vitamin A supplementation $\left(3030 \mu \mathrm{g}\right.$ RE week $\left.{ }^{-1}\right)$ among refugee preschool-aged children in Belize (an increase of $c .12 \mathrm{gl}^{-1}$ vs. $4 \mathrm{gl}^{-1}$ in the placebo group) $)^{33}$.

The effect of vitamin A on risk of anaemia appears to be more variable in pregnancy than in childhood. Panth et al. observed a significant, but transient, rise in $\mathrm{Hb}$ 
Table 3 Vitamin A supplementation trials that examined effects on haematological indicators

\begin{tabular}{|c|c|c|c|c|c|c|}
\hline Reference & $\begin{array}{l}\text { Subject population } \\
\text { (total sample size) }\end{array}$ & $\begin{array}{c}\text { Duration of } \\
\text { supplementation }\end{array}$ & Treatment groups and regimen & $\begin{array}{l}\text { Change in } \\
\text { mean haemoglobin } \\
\left(\mathrm{gl}^{-1}\right)\end{array}$ & $\begin{array}{l}\text { Change in } \\
\text { mean } \\
\text { haematocrit }\end{array}$ & Comments \\
\hline $\begin{array}{l}\text { Muhilal et al. } \\
\qquad(1988)^{31}\end{array}$ & $\begin{array}{l}\text { Indonesia, } \\
\text { preschool children } \\
\text { (445) }\end{array}$ & 5 months & $\begin{array}{l}\text { Unfortified MSG } \\
240 \mu \mathrm{g} \text { RE VA/day fortified MSG }\end{array}$ & $\begin{array}{l}-2.0 \\
10.0^{* *}\end{array}$ & Not reported & $\begin{array}{l}\text { Randomization of } \\
\text { villages not } \\
\text { specified }\end{array}$ \\
\hline $\begin{array}{l}\text { Mejia \& Chew } \\
\quad(1988)^{32}\end{array}$ & $\begin{array}{l}\text { Guatemala, } \\
\text { children } 1-8 \text { years } \\
\text { (115) }\end{array}$ & 2 months & $\begin{array}{l}\text { Placebo } \\
1500-3000 \mu \mathrm{g} \mathrm{RE} \mathrm{VA/day} \\
3 \mathrm{mg} / \mathrm{kg} / \mathrm{day} \mathrm{Fe} \\
3 \mathrm{mg} / \mathrm{kg} / \text { day Fe }+1500-3000 \mu \mathrm{g} \mathrm{RE} \mathrm{VA/day}\end{array}$ & $\begin{array}{l}3.2 \\
9.3 \\
13.8^{\star \star} \\
14.2^{\star \star}\end{array}$ & Not reported & $\begin{array}{l}\text { Anaemic } \\
\text { population } \\
\text { Blinding status } \\
\text { unknown }\end{array}$ \\
\hline $\begin{array}{l}\text { Smith et al. } \\
(1999)^{33}\end{array}$ & $\begin{array}{l}\text { Belize, } \\
\text { preschool children } \\
\text { (51) }\end{array}$ & 6 months & $\begin{array}{l}\text { Placebo } \\
70 \mathrm{mg} \mathrm{Zn/week} \\
3030 \mu \mathrm{g} \mathrm{RE} \mathrm{VA/week} \\
70 \mathrm{mg} \mathrm{Zn}+3030 \mu \mathrm{g} \mathrm{RE} \mathrm{VA/week}\end{array}$ & $\begin{array}{c}4.0 \\
8.0^{\star} \\
12.0^{\star \star} \\
11.0^{\star \star}\end{array}$ & Not reported & $\begin{array}{l}\text { Children selected } \\
\text { for low/marginal } \\
\text { initial serum Zn } \\
\text { and VA } \\
\text { concentrations }\end{array}$ \\
\hline $\begin{array}{l}\text { Panth et al. } \\
\qquad(1990)^{34}\end{array}$ & $\begin{array}{l}\text { India, } \\
\text { pregnant women } \\
(450)\end{array}$ & $6-24$ weeks & $\begin{array}{l}60 \mathrm{mg} \mathrm{Fe} / \text { day } \\
1800 \mu \mathrm{g} \mathrm{RE} \mathrm{VA} / \text { day }+60 \mathrm{mg} \text { Fe/day }\end{array}$ & Not reported & Not reported & $\begin{array}{l}\text { Analysis of } \mathrm{Hb} \\
\text { changes was } \\
\text { cross-sectional }\end{array}$ \\
\hline $\begin{array}{l}\text { Suharno et al. } \\
\quad(1993)^{35}\end{array}$ & $\begin{array}{l}\text { Indonesia, } \\
\text { pregnant women } \\
(305)\end{array}$ & 8 weeks & $\begin{array}{l}\text { Placebo } \\
2400 \mu \mathrm{g} \mathrm{RE} \mathrm{VA/day} \\
60 \mathrm{mg} \mathrm{Fe} / \text { day } \\
2400 \mu \mathrm{g} \mathrm{RE} \mathrm{VA/day}+60 \mathrm{mg} \mathrm{Fe/day}\end{array}$ & $\begin{array}{l}2.0 \\
6.0^{\star \star} \\
10.0^{\star \star} \\
15.0^{\star *}\end{array}$ & $\begin{array}{l}0.01 \\
0.02^{\star \star} \\
0.03^{\star \star} \\
0.05^{\star \star}\end{array}$ & $\begin{array}{l}\text { Anaemic } \\
\text { population }\end{array}$ \\
\hline $\begin{array}{l}\text { Shatrugna } \\
\text { et al. } \\
(1997)^{36}\end{array}$ & $\begin{array}{l}\text { India, } \\
\text { pregnant women } \\
(145)\end{array}$ & $12-16$ weeks & $\begin{array}{l}500 \mu \mathrm{g} \text { folic acid }+120 \mathrm{mg} \mathrm{Fe} / \text { day } \\
500 \mu \mathrm{g} \text { folic acid }+60 \mathrm{mg} \mathrm{Fe} / \text { day } \\
500 \mu \mathrm{g} \text { folic acid }+60 \mathrm{mg} \mathrm{Fe}+1800 \mu \mathrm{g} \mathrm{RE} \mathrm{VA} / \text { day }\end{array}$ & $\begin{array}{l}9.2 \\
8.5 \\
8.9\end{array}$ & Not reported & $\begin{array}{l}\text { Randomization and } \\
\text { blinding not clear }\end{array}$ \\
\hline $\begin{array}{l}\text { Fawzi et al. } \\
\quad(1998)^{37}\end{array}$ & $\begin{array}{l}\text { Tanzania, } \\
\text { HIV+ pregnant } \\
\text { women } \\
(1075)\end{array}$ & 13-28 weeks & $\begin{array}{l}\text { Placebo } \\
6500 \mu \mathrm{g} \text { RE VA/day } \\
6500 \mu \mathrm{g} \text { RE VA/day + multivitamins } \\
\text { Multivitamins w/o VA }\end{array}$ & $\begin{array}{l}\text { Group means not } \\
\text { reported }\end{array}$ & Not reported & $\begin{array}{l}\text { No significant Hb } \\
\text { difference } \\
\text { between groups } \\
\text { given VA and } \\
\text { groups not } \\
\text { given VA }\end{array}$ \\
\hline
\end{tabular}




\begin{tabular}{|c|c|c|c|c|c|c|}
\hline $\begin{array}{l}\text { Bloem et al. } \\
\quad(1990)^{39}\end{array}$ & $\begin{array}{l}\text { Thailand, } \\
\text { children 3-9 years } \\
\text { (134) }\end{array}$ & $\begin{array}{l}\text { Single dose } \\
2 \text { week follow-up }\end{array}$ & $\begin{array}{l}\text { No supplement } \\
110 \mathrm{mg} \text { RE VA }\end{array}$ & $\begin{array}{l}-0.8 \\
2.2^{*}\end{array}$ & $\begin{array}{l}-0.01 \\
-0.001^{*}\end{array}$ & $\begin{array}{l}\text { VA deficient } \\
\text { Not double blinded }\end{array}$ \\
\hline $\begin{array}{l}\text { Semba et al. } \\
\quad(1992)^{40}\end{array}$ & $\begin{array}{l}\text { Indonesia, } \\
\text { children } 3-6 \text { years } \\
\text { (236) }\end{array}$ & $\begin{array}{l}\text { Single dose } \\
5 \text { week follow-up }\end{array}$ & $\begin{array}{l}\text { Xerophthalmic children: } \\
\text { Placebo } \\
60000 \mu \mathrm{g} \text { RE VA } \\
\text { Clinically normal children: } \\
\text { Placebo } \\
60000 \mu \mathrm{g} \text { RE VA } \\
\text { All children with } \mathrm{Hb}<11.0 \mathrm{gl}^{-1} \text { : } \\
\text { Placebo } \\
60000 \mu \mathrm{g} \text { RE VA }\end{array}$ & $\begin{array}{c}5.0 \\
5.0 \\
5.0 \\
5.0 \\
14.0 \\
21.0^{\star}\end{array}$ & Not reported & $\begin{array}{l}\text { VA deficient } \\
\text { Majority non- } \\
\text { anaemic }\end{array}$ \\
\hline $\begin{array}{l}\text { Bloem et al. } \\
\quad(1989)^{26}\end{array}$ & $\begin{array}{l}\text { Thailand, } \\
\text { children } 1-6 \text { years } \\
\text { (166) }\end{array}$ & $\begin{array}{l}\text { Single dose } \\
4 \text { month follow-up }\end{array}$ & $\begin{array}{l}\text { No supplement } \\
110 \mathrm{mg} \text { RE VA }+40 \mathrm{mg} \text { VE }\end{array}$ & $\begin{array}{l}2.4 \\
2.0\end{array}$ & $\begin{array}{l}0.01 \\
0.01\end{array}$ & $\begin{array}{l}\text { Anaemic } \\
\text { population } \\
\text { Not double blinded } \\
\text { VA dietary intake } \\
\text { increased over } \\
\text { course of study } \\
\text { among both } \\
\text { groups }\end{array}$ \\
\hline $\begin{array}{l}\text { Chawla \& Puri } \\
\quad(1995)^{41}\end{array}$ & $\begin{array}{l}\text { India, } \\
\text { pregnant women } \\
(81)\end{array}$ & 15 weeks & $\begin{array}{l}\text { No supplement } \\
60 \mathrm{mg} \mathrm{Fe}+500 \mu \mathrm{g} \text { folic acid/day } \\
60 \mathrm{mg} \mathrm{Fe}+500 \mu \mathrm{g} \text { folic acid/day }+60000 \mu \mathrm{g} \mathrm{RE} \mathrm{VA}(1 \times)\end{array}$ & $\begin{array}{l}-6.0 \\
3.0^{* *} \\
5.0^{* *}\end{array}$ & $\begin{array}{l}-0.018 \\
0.007^{\star *} \\
0.015^{\star *}\end{array}$ & $\begin{array}{l}\text { Not randomized } \\
\text { Not double blinded }\end{array}$ \\
\hline $\begin{array}{l}\text { Kolsteren et al. } \\
(1999)^{42}\end{array}$ & $\begin{array}{l}\text { Bangladesh, } \\
\text { non-pregnant women } \\
(216)\end{array}$ & 2 months & $\begin{array}{l}60 \mathrm{mg} \mathrm{Fe} / \text { day } \\
60 \mathrm{mg} \mathrm{Fe} / \mathrm{day}+60000 \mu \mathrm{g} \mathrm{RE} \mathrm{VA}(1 \times) \\
60 \mathrm{mg} \mathrm{Fe} / \text { day }+15 \mathrm{mg} \mathrm{Zn/day}+60000 \mu \mathrm{g} \mathrm{RE} \mathrm{VA}(1 \times)\end{array}$ & $\begin{array}{l}13.4 \\
15.9 \\
17.9^{\star}\end{array}$ & Not reported & $\begin{array}{l}\text { Anaemic } \\
\text { population } \\
\text { Not VA deficient } \\
\text { Double blinded? }\end{array}$ \\
\hline
\end{tabular}

MSG, monosodium glutamate; RE, retinol equivalents; VA, vitamin A; w/o, without.

${ }^{*} P<0.05$ relative to control group. 
concentration at 26-28 weeks of gestation among Indian women supplemented with $1800 \mu \mathrm{g}$ RE plus $60 \mathrm{mg}$ of iron day $^{-1}$ compared to iron alone ${ }^{34}$. In Indonesia, midgestational anaemic women received $2400 \mu \mathrm{g}$ RE of vitamin A, oral iron, vitamin A plus iron, or placebo daily for 8 weeks $^{35}$. Mean $\mathrm{Hb}$ concentrations increased by 6,10 and $15 \mathrm{~g} \mathrm{l}^{-1}$ as the prevalence of anaemia declined by $23 \%, 62 \%$ and $98 \%$ in the three treatment groups, respectively, suggesting that about a quarter of the prevalence of anaemia in this population could be prevented with vitamin A alone. Combining vitamin A with iron increased serum iron and transferrin saturation values more than either nutrient alone. In contrast, the addition of vitamin $\mathrm{A}(1800 \mu \mathrm{g} \mathrm{RE})$ to daily iron $(60 \mathrm{mg})$ had no additional effect on $\mathrm{Hb}$ concentration in pregnant Indian women ${ }^{36}$. And, among pregnant women infected with human immunodeficiency virus (HIV)-1, in Tanzania, daily supplementation with $c .6500 \mu \mathrm{g}$ RE (as $\beta$-carotene and preformed vitamin A) lacked a measurable effect on $\mathrm{Hb}$ concentration ${ }^{37}$. Reasons for a variable haematological response to vitamin $\mathrm{A}$ in pregnant women are not well understood, but may relate to inadequate dosage in the presence of poor absorption and increased requirements in malnourished and diseased states, such as HIV or AIDS. Plasma volume expansion and haemodilution during the first two trimesters of pregnancy may also obscure haematological responses to supplementation ${ }^{38}$.

Large, single dose supplements of vitamin A have produced positive haematological effects. For example, randomized trials among preschool and early schoolaged children in Thailand ${ }^{39}$ and Indonesia ${ }^{40}$ have shown 60-110 mg RE doses to increase serum or plasma ferritin, and transferrin saturation, without affecting $\mathrm{Hb}$ or Hct, except among children with low initial $\mathrm{Hb}$ concentrations $\left(<110 \mathrm{gl}^{-1}\right)^{26,39,40}$. In contrast, other studies have shown high-potency vitamin A to elevate $\mathrm{Hb}$ and serum iron but not serum ferritin ${ }^{39}$. Among anaemic and mildly vitamin Adeficient pregnant women in India, a single $60000 \mu \mathrm{g}$ RE dose of vitamin A added to daily supplementation of iron and folic acid resulted in a mean increase in $\mathrm{Hb}$ concentration (of $2 \mathrm{gl}^{-1}$ ) and Hct, and, compared to treatment with iron and folic acid alone, lessened the severity of the decline in serum iron ${ }^{41}$. A similar (but in this case, not statistically significant) rise in $\mathrm{Hb}$ concentration of $3 \mathrm{~g} \mathrm{l}^{-1}$ was obtained in non-pregnant, anaemic Bangladeshi women in response to a large, single oral dose of vitamin A (200000 IU) when given with daily iron relative to iron alone ${ }^{42}$. A combination of vitamin A with daily iron and zinc raised $\mathrm{Hb}$ concentration by $5 \mathrm{gl}^{-1} \quad(P<0.05)$ above that associated with iron alone. The greater response observed in the presence of zinc could reflect increased vitamin A mobilization, as zinc supplementation has been associated with increases in plasma vitamin A and retinol-binding protein ${ }^{43}$.

Parasitic infections may modify the impact of vitamin A on anaemia. Among predominantly anaemic pregnant women in Nepal receiving $7000 \mu \mathrm{g}$ RE week $^{-1}$, anaemia was reduced by $c .9 \%$ during pregnancy and postpartum relative to a placebo group ${ }^{44}$. Vitamin A, however, was unable to compensate for the effect of blood loss associated with hookworm infection: there was no measurable effect of vitamin A among heavily hookworm-infected women (>1000 eggs $\mathrm{g}^{-1}$ ). Among women having light or no worm load, the prevalence of iron deficiency anaemia $\left(\mathrm{Hb}<110 \mathrm{gl}^{-1}\right.$ with erythrocyte protoporphyrin $>90 \mu \mathrm{mol} \mathrm{mol}^{-1}$ or serum ferritin $<12 \mu \mathrm{gl}^{-1}$ ) was $46 \%$ lower in the vitamin A group relative to the placebo group.

Vitamin A deficiency may induce anaemia by impairing the differentiation and proliferation of pluripotent haematopoietic cells ${ }^{13,45,46}$; disturbing renal and hepatic erythropoietin synthesis ${ }^{47}$; reducing mobilization of body iron stores and disturbing iron and haem metabolism ${ }^{13,48}$; through sequestration of iron during the acute phase response to infection ${ }^{49,50}$; or via other mechanisms such as iron absorption (Fig. 1). In Venezuela, for example, provitamin A carotenoid enrichment increased iron absorption from cereals such as corn, rice and wheat, and appeared to counteract inhibitory effects of tea and coffee served with meals ${ }^{51,52}$.

In summary, vitamin A deficiency is consistent in its association with anaemia. Vitamin A supplementation can generally be expected to:

1. Increase $\mathrm{Hb}$ and serum ferritin concentrations of anaemic children and pregnant women.

2. Improve the iron supply to haematopoietic tissue, possibly by enhancing the mobilization of iron delivery, and increasing plasma iron and transferrin saturation.

\section{Folate}

Alongside iron and vitamin $\mathrm{B}_{12}$, folate is a central component of human erythropoiesis, and although widely distributed in foods, especially green leaves ('foliage'), dietary folate deficiency is the leading cause of megaloblastic anaemia in the world ${ }^{53}$. When deficient in folate, the synthesis phase of cell division is prolonged, and germ cell maturation is retarded, leading, in the case of bone marrow, to abnormal red cell precursors (megaloblasts) that have larger than normal cell and nuclear diameters ${ }^{54-57}$. Megaloblasts undergo grossly disturbed cell proliferation, and those that mature are often ingested and degraded by bone marrow macrophages. As a result, erythropoiesis is ineffective, the rate of delivery of new erythrocytes into circulation is depressed, and a macrocytic anaemia gradually develops (Fig. 1). Haematologically, this may be reflected in a high mean (corpuscular) cell volume (MCV) and low $\mathrm{Hb}$ concentration ${ }^{57}$.

Pregnant women are at high risk for folate deficiency and megaloblastic anaemia during pregnancy ${ }^{58-60}$. Preterm infants have lower folate body stores at birth and 
higher growth demands as almost two-thirds of preterm infants experience low serum folate levels between 1 and 3 months of age ${ }^{53,61-63}$. Populations in malaria-endemic regions are at a high risk of folate deficiency, as well. The extensive haemolysis brought on by malaria stimulates erythroid hyperplasia and drastically increases the requirement for folate, making malaria during pregnancy the most common cause of megaloblastic erythropoiesis in West Africa ${ }^{64}$.

Table 4 summarizes trials that have investigated the effects of folic acid supplementation on $\mathrm{Hb}$ concentration and Hct, while a few others have reported effects on neutrophil hypersegmentation, a functional measure of abnormal folate metabolism. Folic acid supplementation can prevent megaloblastic erythropoiesis among severely folate-deficient individuals, but the extent to which this translates into increases in $\mathrm{Hb}$ concentrations of public health importance among generally malnourished and subclinically deficient populations is not known. Folate trials have focused predominantly on effects during pregnancy. Although a few studies have noted improvement in $\mathrm{Hb}$ concentrations, most studies have been unable to demonstrate this effect in the absence of severe, overt folic acid deficiency or megaloblastic erythropoiesis. Modest and statistically non-significant increases in $\mathrm{Hb}$ concentrations of $1-6 \mathrm{gl}^{-1}$ have been consistently reported among studies of anaemic and non-anaemic, pregnant women in Burma ${ }^{65}$, Thailand ${ }^{66,67}$, India ${ }^{6-71}$, Nigeria ${ }^{72}$, Liberia $^{73}$ and Australia ${ }^{74}$, employing supplemental doses of folic acid ranging from 0.5 to $5 \mathrm{mg} \mathrm{day}^{-1}$, compared to placebo, iron alone or iron in combination with vitamin $\mathrm{B}_{12}$. One study, in South Africa, has reported a significant improvement in $\mathrm{Hb}^{75}$. Women receiving 300-1000 $\mu \mathrm{g}$ $\mathrm{day}^{-1}$ of folate, as fortified maize, during the last month of pregnancy exhibited $\mathrm{Hb}$ gains of 5.0-8.5 $\mathrm{gl}^{-1}$ compared to a $\mathrm{Hb}$ decline of $-6.9 \mathrm{gl}^{-1}$ among women receiving unfortified maize. These results would be unexpected, given that women were not anaemic at baseline, and the study lasted for only a few weeks.

Although these trials indicate that folate supplementation fails to raise $\mathrm{Hb}$ concentration or lower the risk of anaemia, it can prevent development of megaloblastosis. For example, in a randomized, placebo-controlled trial among non-anaemic pregnant women in Australia, folic acid supplementation significantly reduced the percentage of hypersegmented neutrophils by the time of delivery ${ }^{74}$. In a second trial, among 200 primigravids in Nigeria, $8 \%$ of women receiving daily folic acid with antimalarial prophylaxis exhibited megaloblastic erythropoiesis (based on blood examination of red cell morphology) at follow-up compared to $25 \%$ receiving antimalarial prophylaxis without folic acid and 56\% in the placebo group ${ }^{76}$.

Folic acid has also had little effect on Hb concentration among non-pregnant women. Three months of daily supplementation with $1 \mathrm{mg}$ folic acid and multivitamin during the postpartum period produced slight, though significant, increases in mean $\mathrm{Hb}$ and Hct levels $\left(2 \mathrm{gl}^{-1}\right.$ and and 0.008 , respectively) compared to multivitamin use alone among lactating American women ${ }^{77}$. However, no benefit of folic acid supplementation on $\mathrm{Hb}$ response was observed in trials among either non-pregnant Thai women $^{67}$ or Malaysian adolescent girls ${ }^{78}$. In the latter study, however, plasma ferritin increased significantly following supplementation with iron and folate, but decreased in the folate-alone group, suggesting that folate may have stimulated synthesis of $\mathrm{Hb}$ from existing iron stores. In Thai school-aged children, hospitalized for malaria, 5 weeks of folic acid supplementation $(15 \mathrm{mg}$ $\mathrm{day}^{-1}$ ), failed to increase $\mathrm{Hb}$ and Hct levels beyond those achieved by placebo ${ }^{79}$.

Premature and low birth weight infants are highly susceptible to folate deficiency in the first year of life, and megaloblastic anaemia is common among them by 6-8 weeks of age ${ }^{80}$. However, in this age group as well, $\mathrm{Hb}$ appears to respond poorly to folate supplementation. In Britain, parenteral folic acid ${ }^{61}$ and oral folic acid ${ }^{81}$ given to low birth weight infants failed to improve $\mathrm{Hb}$ concentrations, while in a third trial ${ }^{82}$, oral folic acid $(100 \mu \mathrm{g})$ appeared to temper the decline in $\mathrm{Hb}$ at 8 weeks and significantly increase $\mathrm{Hb}$ by $23 \mathrm{gl}^{-1}$ at 6 months. However, the folate group had significantly higher $\mathrm{Hb}$ levels at baseline, the infants were not randomized, and the groups were fed differently ${ }^{82}$.

Stronger evidence of $\mathrm{Hb}$ improvement has been observed. In southwest England, infants weighing $<2.5 \mathrm{~kg}$ received either $100 \mu \mathrm{g} \mathrm{day}^{-1}$ oral folic acid with $10 \mathrm{mg} \mathrm{day}^{-1}$ iron or iron alone for 12 months $^{83}$. At 6 and 9 months, mean $\mathrm{Hb}$ was significantly higher in the iron plus folate group compared with those receiving iron alone (by c. $4-5 \mathrm{gl}^{-1}$ ) and still slightly, but not significantly, higher at 12 months. In a trial of $0.1 \mathrm{mg}$ oral folic acid with or without $100 \mu \mathrm{g}$ parenteral vitamin $\mathrm{B}_{12}$ among premature infants weighing $<1800 \mathrm{~g}$ in the USA, $\mathrm{Hb}$ declined among all infants, reaching a nadir at age 1012 weeks. Relative to a mean $\mathrm{Hb}$ drop of $70 \mathrm{gl}^{-1}$ in the control group, however, folic acid supplementation significantly reduced the severity of the decline $\left(-51 \mathrm{gl}^{-1}\right)$, though by 6 months of age $\mathrm{Hb}$ concentrations were comparable in both folate-supplemented and control infants ${ }^{84}$.

To conclude, folic acid deficiency contributes to anaemia primarily by disrupting cell division which compromises erythropoiesis. Supplementation with folic acid is effective in treating and preventing severe folate deficiency and overt megaloblastic anaemia. However, trials to date indicate that folic acid supplementation:

1. Has little effect on $\mathrm{Hb}$ concentration or Hct status among pregnant women.

2. May lessen the severity of anaemia of prematurity among young infants, although no large trials have 
Table 4 Folic acid supplementation trials that examined effects on haematological indicators

\begin{tabular}{|c|c|c|c|c|c|c|}
\hline Reference & $\begin{array}{l}\text { Subject population } \\
\text { (total sample size) }\end{array}$ & $\begin{array}{c}\text { Duration of } \\
\text { supplementation }\end{array}$ & Treatment groups and regimen & $\begin{array}{l}\text { Change in } \\
\text { mean haemoglobin } \\
\left(\mathrm{gl}^{-1}\right)\end{array}$ & $\begin{array}{l}\text { Change in } \\
\text { mean } \\
\text { haematocrit }\end{array}$ & Comments \\
\hline $\begin{array}{l}\text { Batu et al. } \\
(1976)^{65}\end{array}$ & $\begin{array}{l}\text { Burma, } \\
\text { pregnant women } \\
\text { (133) }\end{array}$ & 16 weeks & $\begin{array}{l}\text { Placebo } \\
120 \mathrm{mg} \mathrm{Fe} / \text { day } \\
10 \mathrm{mg} \text { folic acid/day } \\
120 \mathrm{mg} \mathrm{Fe}+10 \mathrm{mg} \text { folic acid/day }\end{array}$ & $\begin{array}{r}-7.0 \\
4.0 \\
-7.0 \\
7.0\end{array}$ & Not reported & $\begin{array}{l}\text { Predominantly } \\
\text { anaemic } \\
\text { population }\end{array}$ \\
\hline $\begin{array}{l}\text { Srisupandit et al. } \\
(1983)^{66}\end{array}$ & $\begin{array}{l}\text { Thailand, } \\
\text { pregnant women } \\
\text { (567) }\end{array}$ & 12 weeks & $\begin{array}{l}60 \mathrm{mg} \mathrm{Fe} / \text { day } \\
180 \mathrm{mg} \mathrm{Fe} / \text { day } \\
180 \mathrm{mg} \mathrm{Fe}+5 \mathrm{mg} \text { folic acid/day }\end{array}$ & $\begin{array}{l}7.6 \\
9.0 \\
8.3\end{array}$ & Not reported & $\begin{array}{l}\text { Not placebo controlled } \\
\text { Blinded? }\end{array}$ \\
\hline $\begin{array}{l}\text { Valyasevi et al. } \\
(1988)^{67} \dagger\end{array}$ & $\begin{array}{l}\text { Thailand, } \\
\text { pregnant women } \\
\text { (325) }\end{array}$ & 15 weeks & $\begin{array}{l}\text { Placebo } \\
5 \mathrm{mg} \text { folic acid }+120 \mathrm{mg} \mathrm{Fe} / \text { day } \\
5 \mathrm{mg} \text { folic acid }+240 \mathrm{mg} \mathrm{Fe} / \text { day } \\
240 \mathrm{mg} \mathrm{Fe} / \text { day } \\
5 \mathrm{mg} \text { folic acid }+120 \mathrm{mg} \mathrm{Fe} / \text { day (unsupervised) } \\
5 \mathrm{mg} \text { folic acid }+240 \mathrm{mg} \mathrm{Fe} / \text { day (unsupervised) }\end{array}$ & $\begin{array}{l}-0.7 \\
14.4^{\star \star} \\
13.0^{\star \star} \\
12.1^{\star \star} \\
12.7^{\star \star} \\
12.9^{\star \star}\end{array}$ & Not reported & $\begin{array}{l}\text { Predominantly } \\
\text { anaemic } \\
\text { population } \\
\text { Not double blinded }\end{array}$ \\
\hline $\begin{array}{l}\text { Thanangkul et al. } \\
(1988)^{67} \dagger\end{array}$ & $\begin{array}{l}\text { Thailand, } \\
\text { non-pregnant women } \\
(377)\end{array}$ & 3 months & $\begin{array}{l}\text { Village A: } \\
\text { Placebo } \\
120 \mathrm{mg} \mathrm{Fe} / \text { day } \\
240 \mathrm{mg} \mathrm{Fe} / \mathrm{day} \\
240 \mathrm{mg} \mathrm{Fe}+5 \mathrm{mg} \text { folic acid/day } \\
\text { Village B: } \\
\text { Placebo } \\
120 \mathrm{mg} \mathrm{Fe} / \text { day } \\
240 \mathrm{mg} \mathrm{Fe} / \text { day } \\
240 \mathrm{mg} \mathrm{Fe}+5 \mathrm{mg} \text { folic acid/day }\end{array}$ & $\begin{array}{c}0.2 \\
11.8^{\star \star} \\
6.9^{\star} \\
11.4^{\star \star} \\
\\
\\
-2.5 \\
3.3 \\
5.0 \\
0.5\end{array}$ & Not reported & $\begin{array}{l}\text { Village A had } 27 \% \\
\text { prevalence of } \\
\text { anaemia, population } \\
\text { was largely } \\
\text { vegetarian and area } \\
\text { was malaria } \\
\text { endemic } \\
\text { Village B had } 7 \% \\
\text { prevalence of } \\
\text { anaemia, } \\
\text { population was } \\
\text { largely non- } \\
\text { vegetarian and } \\
\text { area was not } \\
\text { malaria endemic }\end{array}$ \\
\hline $\begin{array}{l}\text { Thane Toe et al. } \\
(1988)^{67} \dagger\end{array}$ & $\begin{array}{l}\text { Burma, } \\
\text { pregnant women } \\
(306)\end{array}$ & 12 weeks & $\begin{array}{l}5 \mathrm{mg} \text { folic acid }+60 \mathrm{mg} \mathrm{Fe} / \text { day } \\
5 \mathrm{mg} \text { folic acid }+120 \mathrm{mg} \mathrm{Fe} / \text { day (divided dose) } \\
5 \mathrm{mg} \text { folic acid }+120 \mathrm{mg} \mathrm{Fe} / \text { day } \\
5 \mathrm{mg} \text { folic acid }+240 \mathrm{mg} \mathrm{Fe} / \text { day (divided dose) } \\
5 \mathrm{mg} \text { folic acid }+240 \mathrm{mg} \mathrm{Fe} / \text { day } \\
240 \mathrm{mg} \mathrm{Fe} / \text { day (divided dose) } \\
5 \mathrm{mg} \text { folic acid }+120 \mathrm{mg} \mathrm{Fe} / \text { day (unsupervised) } \\
5 \mathrm{mg} \text { folic acid }+240 \mathrm{mg} \mathrm{Fe} / \text { day (divided dose, unsupervised) }\end{array}$ & $\begin{array}{l}5.4 \\
6.6 \\
5.5 \\
7.7 \\
4.7 \\
5.8 \\
7.4 \\
2.0\end{array}$ & Not reported & $\begin{array}{l}\text { No significant folic } \\
\text { acid effect } \\
\text { Blinded? }\end{array}$ \\
\hline $\begin{array}{l}\text { Basu et al. } \\
\quad(1973)^{68}\end{array}$ & $\begin{array}{l}\text { India, } \\
\text { pregnant women } \\
\text { (112) }\end{array}$ & 4 weeks & $\begin{array}{l}\text { Placebo } \\
75 \mathrm{mg} \mathrm{Fe} / \text { day } \\
10 \mu \mathrm{g} \mathrm{B} 1_{12} / \text { day } \\
500 \mu \mathrm{g} \text { folic acid/day } \\
75 \mathrm{mg} \mathrm{Fe}+10 \mu \mathrm{g} \mathrm{B} \text { B }_{12} / \text { day } \\
75 \mathrm{mg} \mathrm{Fe}+500 \mu \mathrm{g} \text { folic acid/day } \\
10 \mu \mathrm{g} \mathrm{B} 1_{12}+500 \mu \mathrm{g} \text { folic acid/day } \\
75 \mathrm{mg} \mathrm{Fe}+10 \mu \mathrm{g} \mathrm{B} \text { B }_{12}+500 \mu \mathrm{g} \text { folic acid/day }\end{array}$ & $\begin{array}{l}\text { Not reported per } \\
\text { group }\end{array}$ & Not reported & $\begin{array}{l}\text { Women receiving Fe } \\
\text { had mean } \mathrm{Hb} \text { rise } \\
\text { of } 1.46 \mathrm{gl}^{-1} \\
\text { Folid acid enhanced } \\
\text { this response by } \\
4.2 \mathrm{gl}^{-1} \\
\text { Anaemic population } \\
\text { not blinded } \\
\text { Short duration of } \\
\text { supplementation }\end{array}$ \\
\hline
\end{tabular}




\begin{tabular}{|c|c|c|}
\hline $\begin{array}{l}\text { Sood et al. } \\
\quad(1975)^{69}\end{array}$ & $\begin{array}{l}\text { India, } \\
\text { pregnant women } \\
(647)\end{array}$ & 10-12 weeks \\
\hline $\begin{array}{l}\text { lyengar \& } \\
\text { Rajalakshmi } \\
(1975)^{70}\end{array}$ & $\begin{array}{l}\text { India, } \\
\text { pregnant women } \\
(500)\end{array}$ & $12-16$ weeks \\
\hline $\begin{array}{l}\text { lyengar \& Apte } \\
(1970)^{71}\end{array}$ & $\begin{array}{l}\text { India, } \\
\text { pregnant women } \\
(768)\end{array}$ & $12-16$ weeks \\
\hline Osifo $(1970)^{72}$ & $\begin{array}{l}\text { Nigeria, } \\
\text { pregnant women } \\
(52)\end{array}$ & $\begin{array}{l}\text { From enrolment } \\
\text { to delivery }\end{array}$ \\
\hline $\begin{array}{l}\text { Jackson \& } \\
\quad \text { Latham (1982) }\end{array}$ & $\begin{array}{l}\text { Liberia, } \\
\text { pregnant women } \\
\text { (621) }\end{array}$ & 12 weeks \\
\hline $\begin{array}{l}\text { Fleming et al. } \\
\qquad(1974)^{74}\end{array}$ & $\begin{array}{l}\text { Australia, } \\
\text { pregnant women } \\
\text { (146) }\end{array}$ & $\begin{array}{l}\text { From mid- } \\
\text { pregnancy to } \\
6-8 \text { weeks } \\
\text { postpartum }\end{array}$ \\
\hline $\begin{array}{l}\text { Colman et al. } \\
\quad(1975)^{75}\end{array}$ & $\begin{array}{l}\text { South Africa, } \\
\text { pregnant women } \\
\text { (122) }\end{array}$ & 4 weeks \\
\hline $\begin{array}{l}\text { Fleming et al. } \\
\quad(1986)^{76}\end{array}$ & $\begin{array}{l}\text { Nigeria, } \\
\text { pregnant women } \\
(200)\end{array}$ & $\begin{array}{l}16 \text { weeks } \\
\quad+6 \text { week } \\
\text { follow-up }\end{array}$ \\
\hline $\begin{array}{l}\text { Mackey \& } \\
\quad \text { Picciano }(1999)^{77}\end{array}$ & $\begin{array}{l}\text { USA, } \\
\text { lactating women } \\
\text { (42) }\end{array}$ & 12 weeks \\
\hline $\begin{array}{l}\text { Tee et al. } \\
(1999)^{78}\end{array}$ & $\begin{array}{l}\text { Malaysia, } \\
\text { adolescent girls } \\
(624)\end{array}$ & 22 weeks \\
\hline
\end{tabular}

lacebo

$\mu \mathrm{g} \mathrm{B}_{12} / \mathrm{qow}+5 \mathrm{mg}$ folic acid/day

$100 \mu \mathrm{g} \mathrm{B}_{12} / \mathrm{qow}+5 \mathrm{mg}$ folic acid $+30 \mathrm{mg} \mathrm{Fe} /$ day 作 $100 \mu \mathrm{g} \mathrm{B}_{12} / \mathrm{qow}+5 \mathrm{mg}$ folic acid $+120 \mathrm{mg} \mathrm{Fe} /$ day $100 \mu \mathrm{g} \mathrm{B}_{12} / \mathrm{qow}+5 \mathrm{mg}$ folic acid $+240 \mathrm{mg} \mathrm{Fe} /$ day $120 \mathrm{mg}$ Fe/day

$60 \mathrm{mg} \mathrm{Fe} / \mathrm{day}$

$60 \mathrm{mg} \mathrm{Fe}+500 \mu \mathrm{g}$ folic acid/day

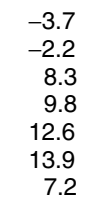

-3.7
-2.2
8.3
9.8
12.6
13.9
7.2

Change not

reported

Placebo

$30 \mathrm{mg} \mathrm{Fe} /$ day

$30 \mathrm{mg} \mathrm{Fe}+500 \mu$ g folic acid/day

$30 \mathrm{mg} \mathrm{Fe}+500 \mu \mathrm{g}$ folic acid $+2 \mu \mathrm{g} \mathrm{B}{ }_{12} /$ day

$120 \mathrm{mg} \mathrm{Fe} /$ day

$120 \mathrm{mg} \mathrm{Fe}+5 \mathrm{mg}$ folic acid/day

$120 \mathrm{mg} \mathrm{Fe}+5 \mathrm{mg}$ folic acid + antimalarial

$40 \mathrm{mg} \mathrm{Fe} / \mathrm{day}$

$20 \mathrm{mg} \mathrm{Fe} / \mathrm{day}$

(20

Antimalarial $+120 \mathrm{mg} \mathrm{Fe}+5 \mathrm{mg}$ folic acid/day

Placebo

$60 \mathrm{mg} \mathrm{Fe} /$ day
$0.5 \mathrm{mg}$ folic acid/da

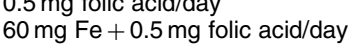

Unfortified maize

$1000 \mu \mathrm{g}$ folic acid-fortified maize/day

$500 \mu \mathrm{g}$ folic acid-fortified maize/day

$300 \mu \mathrm{g}$ folic acid-fortified maize/day

$300 \mu \mathrm{g}$ folic acid tablet/day

Placebo

Antimalarial

Antimalarial $+60 \mathrm{mg} \mathrm{Fe} / \mathrm{day}$

$1 \mathrm{mg}$ folic acid/day

Antimalarial $+60 \mathrm{mg} \mathrm{Fe}+1 \mathrm{mg}$ folic acid/day

Multivitamin + placebo

Multivitamin $+1 \mathrm{mg}$ folic acid

Not reported

Initial Hb 80-119.9 $\mathrm{gl}^{-1}$ :

$60 \mathrm{mg} \mathrm{Fe}+3.5 \mathrm{mg}$ folic acid/week

$120 \mathrm{mg} \mathrm{Fe}+3.5 \mathrm{mg}$ folic acid/week

Initial $\mathrm{Hb} 120-130 \mathrm{gl}^{-1}$

$60 \mathrm{mg} \mathrm{Fe}+3.5 \mathrm{mg}$ folic acid/week

$120 \mathrm{mg} \mathrm{Fe}+3.5 \mathrm{mg}$ folic acid/week

$5 \mathrm{mg}$ folic acid/week
10.0

15.0

6.0

13.0

13.0
16.0

10.2

$15.3^{\star \star}$
12.5

$17.9^{\star \star}$

$5.0^{* *}$

$8.5^{\star *}$

16.1

11.0

16.5
21.5

9.0

16.5

0.0
$2.0^{*}$

21.4

23.1

11.4
13.0

\begin{tabular}{|c|c|}
\hline $\begin{array}{l}-0.004 \\
0.0 \\
0.025 \\
0.027 \\
0.033 \\
0.038 \\
0.025\end{array}$ & $\begin{array}{l}\text { Predominantly } \\
\text { anaemic } \\
\text { population }\end{array}$ \\
\hline Not reported & $\begin{array}{l}\text { Predominantly non- } \\
\text { anaemic population } \\
\text { Double blinded? } \\
\text { High drop-out } \\
\text { Hb higher among } \\
\text { folate group at } \\
38 \text { weeks }\end{array}$ \\
\hline Not reported & $\begin{array}{l}\text { No apparent added } \\
\text { haematological } \\
\text { benefit from folic } \\
\text { acid }\end{array}$ \\
\hline $\begin{array}{l}0.021 \\
0.044 \\
0.046\end{array}$ & $\begin{array}{l}\text { Non-anaemic } \\
\text { population } \\
\text { not randomized, } \\
\text { blinded or placebo } \\
\text { controlled }\end{array}$ \\
\hline Not reported & $\begin{array}{l}\text { Not placebo controlled } \\
\text { High drop-out }\end{array}$ \\
\hline $\begin{array}{l}0.040 \\
0.048^{\star} \\
0.046 \\
0.060^{\star}\end{array}$ & $\begin{array}{c}\text { Non-anaemic } \\
\text { population }\end{array}$ \\
\hline Not reported & $\begin{array}{c}\text { Non-anaemic } \\
\text { population }\end{array}$ \\
\hline Not reported & $\begin{array}{l}\text { Small sample size } \\
\text { High drop-out }\end{array}$ \\
\hline $\begin{array}{c}-0.003 \\
0.008^{*}\end{array}$ & $\begin{array}{l}\text { Non-anaemic } \\
\text { population } \\
\text { Not folate deficient }\end{array}$ \\
\hline Not reported & $\begin{array}{l}\text { Plasma ferritin } \\
\text { increased in Fe- } \\
\text { supplemented } \\
\text { groups and } \\
\text { decreased in } \\
\text { folate-only group }\end{array}$ \\
\hline
\end{tabular}




\begin{tabular}{|c|c|c|c|c|c|c|}
\hline Reference & $\begin{array}{l}\text { Subject population } \\
\text { (total sample size) }\end{array}$ & $\begin{array}{c}\text { Duration of } \\
\text { supplementation }\end{array}$ & Treatment groups and regimen & $\begin{array}{c}\text { Change in } \\
\text { mean haemoglobin } \\
\left(\mathrm{gl}^{-1}\right)\end{array}$ & $\begin{array}{l}\text { Change in } \\
\text { mean } \\
\text { haematocrit }\end{array}$ & Comments \\
\hline $\begin{array}{l}\text { Areekul et al. } \\
\qquad(1980)^{79}\end{array}$ & $\begin{array}{l}\text { Thailand, } \\
\text { children 8-12 years } \\
\text { (10) }\end{array}$ & 5 weeks & $\begin{array}{l}\text { Placebo } \\
15 \mathrm{mg} \text { folic acid/day }\end{array}$ & $\begin{array}{r}20.0 \\
1.0\end{array}$ & $\begin{array}{l}0.04 \\
0.004\end{array}$ & $\begin{array}{l}\text { Randomized? } \\
\text { Small sample size }\end{array}$ \\
\hline $\begin{array}{l}\text { Burland et al. } \\
\quad(1971)^{61}\end{array}$ & $\begin{array}{l}\text { England, } \\
\text { premature infants } \\
(30)\end{array}$ & $\begin{array}{l}4 \text { weeks } \\
\quad+8 \text { month } \\
\text { follow-up }\end{array}$ & $\begin{array}{l}\text { Untreated } \\
100 \mu \mathrm{g} \text { folic acid/qod }\end{array}$ & $\begin{array}{l}-47.0 \\
-62.0\end{array}$ & Not reported & $\begin{array}{l}\text { Not randomized, } \\
\text { not blinded and } \\
\text { small sample size } \\
\text { Folate levels at } \\
\text { baseline not } \\
\text { comparable }\end{array}$ \\
\hline $\begin{array}{l}\text { Kendall et al. } \\
\quad(1974)^{81}\end{array}$ & $\begin{array}{l}\text { Wales, } \\
\text { Low birth weight } \\
\text { infants }(<2500 \mathrm{~g}) \text { at } \\
2 \text { weeks of age } \\
(130)\end{array}$ & 6 months & $\begin{array}{l}\text { Placebo } \\
50 \mu \mathrm{g} \text { folic acid/day }\end{array}$ & $\begin{array}{l}-42.0 \\
-52.0\end{array}$ & Not reported & High drop-out \\
\hline $\begin{array}{l}\text { Roberts et al. } \\
(1972)^{82}\end{array}$ & $\begin{array}{l}\text { England, } \\
\text { premature infants at } \\
1 \text { month of age } \\
(110)\end{array}$ & 5 months & $\begin{array}{l}\text { Untreated } \\
100 \mu \mathrm{g} \text { folic acid/day }\end{array}$ & $\begin{array}{r}-34.0 \\
0.0^{* *}\end{array}$ & Not reported & $\begin{array}{l}\text { Not randomized } \\
\text { Groups fed differently } \\
\text { Folate group had } \\
\text { higher baseline } \mathrm{Hb}\end{array}$ \\
\hline $\begin{array}{l}\text { Stevens et al. } \\
\quad(1979)^{83}\end{array}$ & $\begin{array}{l}\text { England, } \\
\text { Low birth weight } \\
\text { infants }(<2500 \mathrm{~g}) \text { at } \\
3 \text { weeks of age } \\
(246)\end{array}$ & 12 months & $\begin{array}{l}10 \mathrm{mg} \mathrm{Fe} / \text { day } \\
10 \mathrm{mg} \mathrm{Fe} / \text { day }+100 \mu \mathrm{g} \text { folic acid }\end{array}$ & $\begin{array}{l}-28.5 \\
-18.4\end{array}$ & $\begin{array}{l}-0.087 \\
-0.064\end{array}$ & $\begin{array}{l}\text { Not randomized, not } \\
\text { blinded } \\
\text { Hb was significantly } \\
\text { higher in folate } \\
\text { group at } 6 \text { and } \\
9 \text { months }\end{array}$ \\
\hline $\begin{array}{l}\text { Worthington-White } \\
\text { et al. }(1994)^{84}\end{array}$ & $\begin{array}{l}\text { USA, } \\
\text { premature infants } \\
(184)\end{array}$ & $\begin{array}{l}4 \text { months } \\
+2 \text { month } \\
\text { follow-up }\end{array}$ & $\begin{array}{l}\text { No supplement } \\
0.1 \mathrm{mg} \text { folic acid/day } \\
0.1 \mathrm{mg} \text { folic acid/day }+100 \mu \mathrm{g} \mathrm{B}_{12} \mathrm{IM} / \mathrm{month} \\
100 \mu \mathrm{g} \mathrm{B} \mathrm{B}_{12} \mathrm{IM} / \mathrm{month}\end{array}$ & $\begin{array}{l}-45.0 \\
-40.0 \\
-30.0^{\star *} \\
-27.0^{\star *}\end{array}$ & Not reported & Blinded? \\
\hline
\end{tabular}

IM, intramuscular; qod, every other day; qow, every other week.

${ }^{*} P<0.05$ relative to control group.

${ }^{\star *} P<0.01$ relative to control group.
†Published in Charoenlarp et al. $(1988)^{67}$. 
assessed the haematological effect of folate delivery to children.

\section{Vitamin $\mathbf{B}_{12}$}

A second nutritional cause of megaloblastic anaemia is vitamin $\mathrm{B}_{12}$ (cobalamin) deficiency, which can produce macrocytic anaemia, as seen in folate deficiency, as well as extensive neurological impairment. Vitamin $B_{12}$ is an essential cofactor in at least two key transmethylation reactions, one of which closely interrelates with folate in DNA synthesis and haematopoiesis. The conversion of homocysteine to the amino acid methionine requires a $\mathrm{B}_{12}$-dependent enzyme as well as a methyl group donated by the folate compound 5-methyltetrahydrofolate (5-methylTHFA). With deficiency of vitamin $\mathrm{B}_{12}$, the enzyme function is disrupted, methionine formation is impaired, and both 5-methylTHFA and homocysteine accumulate. Through either the trapping of folate in the form of 5-methylTHFA or the failure of methionine synthesis, the levels of the folate compound 5,10-methyleneTHFA are reduced, ultimately leading to impaired synthesis of thymidine. An inadequate supply of thymidine, in turn, impairs DNA synthesis, potentially leading to megaloblastosis and anaemia (Fig. 1) ${ }^{57}$.

Dietary $B_{12}$ deficiency occurs less frequently than folate deficiency, usually resulting from defective absorption rather than insufficient intake ${ }^{85}$. In particular, it is commonly the result of a pathological failure or reduction in the secretion of intrinsic factor, the glycoprotein that binds to and facilitates the transport of vitamin $B_{12}$ into the epithelial cells of the small intestine, a condition referred to as pernicious anaemia ${ }^{57}$. The only natural source of vitamin $\mathrm{B}_{12}$ is its synthesis by certain algae, fungi and bacteria. The best dietary sources are meat products in which $\mathrm{B}_{12}$ has accumulated, via either the animal's ingestion of $\mathrm{B}_{12^{-}}$ containing microorganisms or the synthesis of $\mathrm{B}_{12}$ by the animal's gut flora; higher plants contain virtually no vitamin $\mathrm{B}_{12}$ unless contaminated by microorganisms ${ }^{86}$.

Body stores of $\mathrm{B}_{12}$ among normal, healthy adults are large and would take an estimated 3-4 years of zero intake (and perhaps 20 years of low intake) to deplete, due to an efficient enterohepatic circulation that recycles $B_{12}$ from bile and other intestinal secretions ${ }^{87}$. However, several studies have observed that pregnant women who are strict vegetarians or who consume only minimal amounts of meat products are at high risk for becoming $\mathrm{B}_{12}$ deficient during pregnancy and lactation ${ }^{88,89}$.

Few studies have assessed the haematological benefit of prophylactic vitamin $B_{12}$ supplementation (Table 5), and those studies that have addressed anaemia have either not been designed to isolate the effects of $B_{12}$ from those of iron or folate, or have shown no additional haematological improvement associated with $\mathrm{B}_{12}$. In Israel, $90 \%$ of anaemic pregnant women supplemented with $100 \mathrm{mg}$ iron, $5 \mathrm{mg}$ folic acid and $100 \mu \mathrm{g} \mathrm{B}_{12}$ had an increase in
$\mathrm{Hb}$ concentration of at least $5 \mathrm{gl}^{-1}$, compared with only $22 \%$ in the placebo group, although the specific effect of $\mathrm{B}_{12}$ remained unknown ${ }^{90}$. Among pregnant women in Hyderabad, India, $2 \mu \mathrm{g}$ oral $\mathrm{B}_{12}$ added to $30 \mathrm{mg}$ iron and $500 \mu \mathrm{g}$ folic acid did not produce a response in $\mathrm{Hb}$ concentration significantly different from that of iron and folic acid alone ${ }^{71}$. Among anaemic pregnant women in New Delhi, $10 \mu \mathrm{g} \mathrm{B}_{12}$, either alone or in combination with iron and folate, appeared to have no effect on $\mathrm{Hb}$ concentration, although the sample size was small and supplementation lasted only 4 weeks $^{68}$. A study in New Delhi and Vellore demonstrated a slight, yet statistically significant, additional increase in $\mathrm{Hb}$ concentration $\left(c .5 \mathrm{gl}^{-1}\right)$ from a combination of parenteral $B_{12}$ and folate when given with iron, but the study was not designed to distinguish between the effects of $\mathrm{B}_{12}$ and folate ${ }^{69}$.

The strongest evidence of haematological benefit appears to be among premature infants. In Florida, premature, low birth weight infants were randomized to receive, in addition to their standard treatment of iron and vitamin E, $0.1 \mathrm{mg} \mathrm{day}^{-1}$ oral folate, $100 \mu \mathrm{g} \mathrm{month}^{-1}$ parenteral $\mathrm{B}_{12}$, folate with $\mathrm{B}_{12}$ or no additional supplementation, in order to assess differences in the severity of decline in $\mathrm{Hb}$ concentration that typically occurs in such infants ${ }^{84}$. Groups receiving $B_{12}$ experienced the least decline, with $\mathrm{Hb}$ concentrations falling $10-18 \mathrm{gl}^{-1}$ less than unsupplemented or folate-alone groups. By 6 months of age, the infants who had received $\mathrm{B}_{12}$, either with or without folate, had a significantly higher mean $\mathrm{Hb}$ level than both the unsupplemented and folate-alone groups.

To summarize, deficiency of vitamin $\mathrm{B}_{12}$ is less common than that of folate, but treatment of megaloblastic anaemia with folate alone can mask concomitant vitamin $\mathrm{B}_{12}$ deficiency, which can lead to severe neurological sequelae. Thus, megaloblastic anaemia should be treated with both folate and vitamin $B_{12}$. Few studies have reported the haematological effects of vitamin $\mathrm{B}_{12}$ beyond preventing megaloblastosis. Those conducted suggest that $B_{12}$ supplementation:

1. Has no effect on the Hb level of pregnant women. 2. May improve $\mathrm{Hb}$ status and reduce the severity of the anaemia of prematurity among premature and low birth weight infants.

\section{Riboflavin}

Riboflavin (vitamin $\mathrm{B}_{2}$ ) deficiency has been associated with the development of normochromic, normocytic anaemia that responds favourably to riboflavin supplementation $^{91,92}$. Although riboflavin is ubiquitous in foodstuffs, riboflavin deficiency may be one of the most common vitamin deficiencies among the people of developing nations, particularly in those regions where diets are predominantly rice-based and contain insufficient milk, meat, fish, fresh fruit or vegetables ${ }^{93}$. 
Table 5 Vitamin $B_{12}$ supplementation trials that examined effects on haematological indicators

\begin{tabular}{|c|c|c|c|c|c|c|}
\hline Reference & $\begin{array}{l}\text { Subject population } \\
\text { (total sample size) }\end{array}$ & $\begin{array}{c}\text { Duration of } \\
\text { supplementation }\end{array}$ & Treatment groups and regimen & $\begin{array}{c}\text { Change in } \\
\text { mean haemoglobin } \\
\left(\mathrm{gl}^{-1}\right)\end{array}$ & $\begin{array}{l}\text { Change in } \\
\text { mean } \\
\text { haematocrit }\end{array}$ & Comments \\
\hline $\begin{array}{l}\text { lyengar \& Apte } \\
\qquad(1970)^{71}\end{array}$ & $\begin{array}{l}\text { India, } \\
\text { pregnant women } \\
(768)\end{array}$ & $12-16$ weeks & $\begin{array}{l}\text { Placebo } \\
30 \mathrm{mg} \mathrm{Fe} / \text { day } \\
30 \mathrm{mg} \mathrm{Fe}+500 \mu \mathrm{g} \text { folic acid/day } \\
30 \mathrm{mg} \mathrm{Fe}+500 \mu \mathrm{g} \text { folic acid }+2 \mu \mathrm{g} \mathrm{B}_{12} / \text { day }\end{array}$ & Not reported & Not reported & $\begin{array}{l}\text { No apparent added } \\
\text { haematological } \\
\text { benefit from folic } \\
\text { acid or } B_{12}\end{array}$ \\
\hline $\begin{array}{l}\text { Basu et al. } \\
\quad(1973)^{68}\end{array}$ & $\begin{array}{l}\text { India, } \\
\text { pregnant women } \\
(112)\end{array}$ & 4 weeks & $\begin{array}{l}\text { Placebo } \\
75 \mathrm{mg} \mathrm{Fe} / \text { day } \\
10 \mu \mathrm{g} \mathrm{B}_{12} / \text { day } \\
500 \mu \mathrm{g} \text { folic acid/day } \\
75 \mathrm{mg} \mathrm{Fe}+10 \mu \mathrm{g} \mathrm{B}_{12} / \text { day } \\
75 \mathrm{mg} \mathrm{Fe}+500 \mu \mathrm{g} \text { folic acid/day } \\
10 \mu \mathrm{g} \mathrm{B}_{12}+500 \mu \mathrm{g} \text { folic acid/day } \\
75 \mathrm{mg} \mathrm{Fe}+10 \mu \mathrm{g} \mathrm{B}_{12}+500 \mu \mathrm{g} \text { folic acid/day }\end{array}$ & $\begin{array}{l}\text { Not reported per } \\
\text { group }\end{array}$ & Not reported & $\begin{array}{l}\text { Anaemic population } \\
\text { Not blinded } \\
\text { Short duration of } \\
\quad \text { supplementation }\end{array}$ \\
\hline $\begin{array}{l}\text { Sood et al. } \\
\quad(1975)^{69}\end{array}$ & $\begin{array}{l}\text { India, } \\
\text { pregnant women } \\
(647)\end{array}$ & 10-12 weeks & $\begin{array}{l}\text { Placebo } \\
100 \mu \mathrm{g} \mathrm{B} \\
100 \mu \mathrm{g} \mathrm{B}_{12} / \mathrm{qow}+5 \mathrm{mg} \text { folic acid }+5 \mathrm{mg} \text { folic acid }+30 \mathrm{mg} \mathrm{Fe} / \text { day } \\
100 \mu \mathrm{g} \mathrm{B} \mathrm{B}_{12} / \mathrm{qow}+5 \mathrm{mg} \text { folic acid }+60 \mathrm{mg} \mathrm{Fe} / \text { day } \\
100 \mu \mathrm{g} \mathrm{B} \text { B }_{12} / \mathrm{qow}+5 \mathrm{mg} \text { folic acid }+120 \mathrm{mg} \mathrm{Fe} / \text { day } \\
100 \mu \mathrm{g} \mathrm{B}{ }_{12} / \mathrm{qow}+5 \mathrm{mg} \text { folic acid }+240 \mathrm{mg} \mathrm{Fe} / \text { day } \\
120 \mathrm{mg} \mathrm{Fe} / \text { day }\end{array}$ & $\begin{array}{r}-3.7 \\
-2.2 \\
8.3 \\
9.8 \\
12.6 \\
13.9 \\
7.2\end{array}$ & $\begin{array}{c}-0.004 \\
0.0 \\
0.025 \\
0.027 \\
0.033 \\
0.038 \\
0.025\end{array}$ & $\begin{array}{l}\text { Predominantly } \\
\text { anaemic } \\
\text { population }\end{array}$ \\
\hline $\begin{array}{l}\text { Worthington-White } \\
\text { et al. }(1994)^{84}\end{array}$ & $\begin{array}{l}\text { USA, } \\
\text { premature infants } \\
(184)\end{array}$ & $\begin{array}{l}4 \text { months } \\
+2 \text { month } \\
\text { follow-up }\end{array}$ & $\begin{array}{l}\text { No supplement } \\
0.1 \mathrm{mg} \text { folic acid/day } \\
100 \mu \mathrm{g} \mathrm{B}_{12} \mathrm{IM} / \mathrm{month} \\
0.1 \mathrm{mg} \text { folic acid/day }+100 \mu \mathrm{g} \mathrm{B}_{12} \mathrm{IM} / \text { month }\end{array}$ & $\begin{array}{l}-45.0 \\
-40.0 \\
-27.0^{\star *} \\
-30.0^{\star *}\end{array}$ & Not reported & Blinded? \\
\hline
\end{tabular}

IM, intramuscular; qow, every other week.

$P<0.05$ relative to control group

$P<0.01$ relative to control group. 
In vitro and in vivo studies have described a riboflavindependent mechanism for iron mobilization in which a flavin mononucleotide (FMN)-dependent oxidoreductase catalyses the removal of iron from storage ferritin and makes it available for utilization in haem synthesis (Fig. $1)^{94,95}$. There is also an FMN-dependent oxidase instrumental in the conversion of vitamin $\mathrm{B}_{6}$ to its active form, which ultimately stimulates globin production. In one clinical study, riboflavin supplementation produced a three-fold increase in erythrocyte $\mathrm{B}_{6}$ conversion, followed by a rise in $\alpha$ - and $\beta$-globin chain synthesis ${ }^{96}$. Another possibility suggested by animal studies is that riboflavin affects iron absorption by maintaining the absorptive capacity of gastrointestinal villi, but studies among humans have not yet observed measurable change in iron absorption following riboflavin supplementation ${ }^{97,98}$.

Table 6 summarizes riboflavin supplementation trials that have assessed effects on anaemia. Results have been mixed, but several have shown that riboflavin can significantly improve haematological status and augment the response to iron supplementation. A European study of mildly anaemic pregnant women showed that those who had received daily riboflavin $(9 \mathrm{mg}$ ) along with iron $(60 \mathrm{mg})$ maintained their erythrocyte counts and $\mathrm{Hb}$ and Hct levels while an iron-alone group showed significant reductions in all three indices ${ }^{99}$. In the Gambia, marginally anaemic pregnant or lactating women were randomly allocated to receive daily iron $(30 \mathrm{mg})$, riboflavin $(5 \mathrm{mg})$, or both, for 6 weeks ${ }^{100}$. There were no significant responses in $\mathrm{Hb}$ or $\mathrm{Hct}$ to any iron or riboflavin regimen. Unexpectedly, riboflavin appeared to lower $\mathrm{Hb}$ by c. $10 \mathrm{gl}^{-1}$ among pregnant women, although a small sample size limited the difference from reaching statistical significance. Lactating women receiving both iron and riboflavin had significant increases in plasma iron and ferritin, whereas those receiving iron or riboflavin alone did not. The 6-week duration of supplementation may have been too brief to elicit more substantial responses.

Riboflavin-deficient European children aged 9-12 years receiving $3 \mathrm{mg}$ riboflavin exhibited a non-significant increase of $3 \mathrm{gl}^{-1}$ in $\mathrm{Hb}$ concentration after 3 months, compared with a $4 \mathrm{gl}^{-1}$ decrease in the control group ${ }^{101}$. The $\mathrm{Hb}$ increase $\left(7 \mathrm{gl}^{-1}\right)$ was statistically significant among children with an initial Hb below $135 \mathrm{gl}^{-1}$. In a placebocontrolled trial among mostly anaemic 6-12-year-old Thai children, $6 \mathrm{mg}$ of daily riboflavin with $40 \mathrm{mg}$ iron increased mean $\mathrm{Hb}$ by $4 \mathrm{~g}^{-1}$ above that achieved with iron alone $(P<0.005)^{102}$. Other studies among children have not observed significant haematological effects. For example, in the Gambia, iron and riboflavin given at two different doses to riboflavin-deficient 4-12-year-old children had no impact on iron status beyond that of iron supplementation alone ${ }^{103}$. Likewise, adolescents in Yugoslavia showed no response in mean $\mathrm{Hb}$ or Hct to 2 months of $2 \mathrm{mg} \mathrm{day}^{-1}$ riboflavin supplementation ${ }^{104}$.

Unlike the negative findings in Gambian children, however, riboflavin-deficient Gambian men who received $5 \mathrm{mg}$ of riboflavin with $40 \mathrm{mg}$ day $^{-1}$ of iron showed comparable changes in $\mathrm{Hb}$ concentration, but higher Hct, erythrocyte counts and serum ferritin after 6 weeks than men supplemented with iron alone ${ }^{103}$. In a subgroup of anaemic men, the benefit of riboflavin appeared to be greater, producing a $23 \mathrm{gl}^{-1}$ increase in mean $\mathrm{Hb}$ relative to $19 \mathrm{gl}^{-1}$ in the iron-alone group. Improvement was also seen in Nigeria among 27 men and women who received placebo or $5 \mathrm{mg}$ of riboflavin with or without $50 \mathrm{mg}$ of ascorbic acid for 8 weeks in the absence of iron supplementation $^{105}$. Erythrocyte counts, Hct and $\mathrm{Hb}$ levels all increased significantly in the riboflavin-treated groups, with the greatest $\mathrm{Hb}$ increase $\left(18 \mathrm{gl}^{-1}\right)$ produced by the combination of riboflavin and vitamin $\mathrm{C}$.

Thus, riboflavin deficiency may impair iron mobilization, globin synthesis and, possibly, iron absorption. Supplementation with riboflavin may:

1. Enhance the Hb, Hct and erythrocyte count response to iron supplementation during pregnancy.

2. Improve the haematological status of anaemic children and adults.

\section{Vitamin C}

Vitamin C deficiency has been associated with various forms of anaemia, but it is still unclear whether vitamin $\mathrm{C}$ (ascorbate) is directly involved in haematopoiesis or if anaemia arises indirectly through the interactions of vitamin $\mathrm{C}$ with folate and iron metabolism ${ }^{106}$. In its role as a reducing agent, vitamin $\mathrm{C}$ can facilitate iron absorption from the gastrointestinal tract and enable its mobilization from storage (Fig. 1). Iron and ascorbate form an iron chelate complex that is more soluble in the alkaline environment of the small intestine and, as a result, more easily taken up ${ }^{107-110}$. Supplementation with vitamin C may augment the absorption of dietary iron. The simultaneous consumption of $25-75 \mathrm{mg}$ of vitamin C has been shown to enhance four-fold or more the absorption of the less bioavailable, but more common, non-haem iron ${ }^{109}$. However, ascorbic acid must be consumed at about the same time as iron to be effective ${ }^{111}$. In addition, vitamin $\mathrm{C}$ may counteract the inhibition of iron absorption produced by dietary phytates and tannins ${ }^{109}$. Ascorbic acid also activates the enzyme folic acid reductase, to form tetrahydrofolic acid, the active form of folic acid, which prevents megaloblastic anaemia ${ }^{106,112}$. Vitamin C may also prevent iron loss due to haemorrhaging associated with vitamin C deficiency, or, possibly, prevent haemolysis resulting from compromised cellular antioxidant defence mechanisms ${ }^{106,113}$. Vitamin $\mathrm{C}$ deficiency is evident when serum ascorbate falls below $11.4 \mu \mathrm{moll}^{-1}$. Inadequate status ${ }^{114-116}$ is reflected by a serum ascorbate concentration of $11.5-17 \mu \mathrm{moll}^{-1}$. Groups that have been identified as being at risk of vitamin $\mathrm{C}$ deficiency include pregnant 
Table 6 Riboflavin $\left(B_{2}\right)$ supplementation trials that examined effects on haematological indicators

\begin{tabular}{|c|c|c|c|c|c|c|}
\hline Reference & $\begin{array}{l}\text { Subject population } \\
\text { (total sample size) }\end{array}$ & $\begin{array}{c}\text { Duration of } \\
\text { supplementation }\end{array}$ & Treatment groups and regimen & $\begin{array}{l}\text { Change in } \\
\text { mean haemoglobin } \\
\left(\mathrm{gl}^{-1}\right)\end{array}$ & $\begin{array}{l}\text { Change in } \\
\text { mean } \\
\text { haematocrit }\end{array}$ & Comments \\
\hline $\begin{array}{l}\text { Decker et al. } \\
(1977)^{99}\end{array}$ & $\begin{array}{l}\text { Austria, } \\
\text { pregnant women } \\
(200)\end{array}$ & 2 months & $\begin{array}{l}60 \mathrm{mg} \mathrm{Fe} / \mathrm{day} \\
60 \mathrm{mg} \mathrm{Fe}+9 \mathrm{mg} \mathrm{B}_{2} / \text { day }\end{array}$ & $\begin{array}{r}-3.0 \\
0.0\end{array}$ & $\begin{array}{l}-0.007 \\
-0.002\end{array}$ & \\
\hline $\begin{array}{l}\text { Powers et al. } \\
\qquad(1985)^{100}\end{array}$ & $\begin{array}{l}\text { The Gambia, } \\
\text { pregnant or } \\
\text { lactating women } \\
(81)\end{array}$ & 6 weeks & $\begin{array}{l}\text { Pregnant women }(n=18) \text { : } \\
\text { Placebo } \\
5 \mathrm{mg} \mathrm{B}_{2} / \text { day } \\
30 \mathrm{mg} \mathrm{Fe} / \text { day } \\
30 \mathrm{mg} \mathrm{Fe}^{2} 5 \mathrm{mg} \mathrm{B}_{2} / \text { day } \\
\text { Lactating women }(n=63) \text { : } \\
\text { Placebo } \\
5 \mathrm{mg} \mathrm{B}_{2} / \text { day } \\
30 \mathrm{mg} \mathrm{Fe}_{\text {day }} \\
30 \mathrm{mg} \mathrm{Fe}^{2} 5 \mathrm{mg} \mathrm{B}_{2} / \text { day }\end{array}$ & $\begin{array}{r}7.3 \\
-9.7 \\
7.2 \\
-10.2 \\
\\
2.2 \\
3.4 \\
6.8 \\
6.6\end{array}$ & $\begin{array}{r}0.038 \\
-0.002 \\
0.051 \\
-0.023 \\
\\
0.032 \\
0.029 \\
0.030 \\
0.042\end{array}$ & $\begin{array}{l}\text { Small sample size } \\
\text { Folate deficiency common } \\
\text { Short duration of } \\
\text { supplementation }\end{array}$ \\
\hline $\begin{array}{l}\text { Buzina et al. } \\
\quad(1979)^{101}\end{array}$ & $\begin{array}{l}\text { Yugoslavia, } \\
\text { children } 9-12 \text { years } \\
\text { (58) }\end{array}$ & 3 months & $\begin{array}{l}\text { No supplement } \\
3 \mathrm{mg} \mathrm{B}_{2} / \text { day }\end{array}$ & $\begin{array}{r}-4.0 \\
3.0\end{array}$ & $\begin{array}{r}-0.009 \\
0.006\end{array}$ & $\begin{array}{l}\text { Small sample size } \\
\text { Allocation not random } \\
\text { or placebo controlled }\end{array}$ \\
\hline $\begin{array}{l}\text { Charoenlarp } \\
\text { et al. } \\
(1980)^{102}\end{array}$ & $\begin{array}{l}\text { Thailand, } \\
\text { children 6-12 years } \\
\text { (101) }\end{array}$ & 5 months & $\begin{array}{l}\text { Placebo } \\
40 \mathrm{mg} \mathrm{Fe} / \text { day } \\
40 \mathrm{mg} \mathrm{Fe}+6 \mathrm{mg} \mathrm{B}_{2} / \text { day }\end{array}$ & $\begin{array}{l}-1.2 \\
4.8^{\star \star} \\
8.6^{\star \star}\end{array}$ & $\begin{array}{l}-0.011 \\
0.004^{\star *} \\
0.014^{\star *}\end{array}$ & $\begin{array}{l}\text { Predominantly anaemic } \\
\text { population }\end{array}$ \\
\hline $\begin{array}{l}\text { Powers et al. } \\
\qquad(1983)^{103}\end{array}$ & $\begin{array}{l}\text { The Gambia, } \\
\text { children } 4-12 \text { years ( } 80) \\
\text { and adult men ( } 80)\end{array}$ & 6 weeks & $\begin{array}{l}\text { Children: } \\
\text { Placebo } \\
20 \text { or } 40 \mathrm{mg} \mathrm{Fe} / \text { day } \\
20 \text { or } 40 \mathrm{mg} \mathrm{Fe}+2.5 \text { or } 5 \mathrm{mg} \mathrm{B}_{2} / \text { day } \\
\text { Adult men: } \\
\text { Placebo } \\
40 \mathrm{mg} \mathrm{Fe} / \text { day } \\
40 \mathrm{mg} \mathrm{Fe}+5 \mathrm{mg} \mathrm{B}_{2} / \text { day }\end{array}$ & $\begin{array}{l}0.6 \\
14.5^{\star \star} \\
8.5^{\star \star} \\
-2.0 \\
12.9^{\star \star} \\
12.2^{\star \star}\end{array}$ & $\begin{array}{l}0.026 \\
0.051^{\star} \\
0.048^{\star \star} \\
-0.020 \\
0.015^{\star \star} \\
0.022^{\star \star}\end{array}$ & $\begin{array}{l}\text { Predominantly anaemic } \\
\text { population }\end{array}$ \\
\hline $\begin{array}{l}\text { Suboticanec } \\
\text { et al. } \\
(1990)^{104}\end{array}$ & $\begin{array}{l}\text { Croatia, } \\
\text { school children } 12-14 \text { years } \\
\text { (115) }\end{array}$ & 2 months & $\begin{array}{l}\text { Placebo } \\
2 \mathrm{mg} \mathrm{B}_{6} / \text { day } \\
2 \mathrm{mg} \mathrm{B}_{2} / \text { day }\end{array}$ & $\begin{array}{r}2.0 \\
1.0 \\
-1.0\end{array}$ & $\begin{array}{l}-0.007 \\
-0.012 \\
0.0\end{array}$ & Non-anaemic population \\
\hline $\begin{array}{l}\text { Ajayi et al. } \\
\quad(1990)^{105}\end{array}$ & $\begin{array}{l}\text { Nigeria, } \\
\text { adult men and women } \\
\text { (27) }\end{array}$ & 8 weeks & $\begin{array}{l}\text { Placebo } \\
5 \mathrm{mg} \mathrm{B}_{2} / \text { day } \\
5 \mathrm{mg} \mathrm{B}_{2}+50 \mathrm{mg} \mathrm{VC/day}\end{array}$ & $\begin{array}{l}-4.0 \\
14.8^{\star \star} \\
17.8^{\star \star}\end{array}$ & $\begin{array}{l}-0.02 \\
0.04^{\star \star} \\
0.05^{\star \star}\end{array}$ & Controlled experimental study \\
\hline
\end{tabular}

VC, vitamin C.

$P<0.05$ relative to control group.

$* P<0.01$ relative to control group. 
and lactating women, infants fed exclusively cow's milk, elderly men and smokers ${ }^{116-118}$.

A number of trials have assessed the effects of vitamin C supplementation on iron status and anaemia in children and adult pregnant and non-pregnant women (Table 7). Anaemic preschool Indian children receiving $200 \mathrm{mg}$ day $^{-1}$ of ascorbic acid for 2 months showed improved red blood cell morphology and a significant increase in mean $\mathrm{Hb}$ of $19 \mathrm{gl}^{-1}$, whereas $\mathrm{Hb}$ changed little among placebo controls ${ }^{119}$. In northeastern China, $\mathrm{Hb}$ increased significantly by $3-6 \mathrm{gl}^{-1}$ in a dose-responsive manner and serum ferritin rose by $14-28 \mu \mathrm{g}{ }^{-1}$, compared to placebo, among mildly anaemic preschool children receiving $50 \mathrm{mg}$ or more of vitamin $\mathrm{C}$ daily for 2 months ${ }^{120}$. These studies support an adjunct role for vitamin $\mathrm{C}$ in modulating the risk of anaemia in malnourished child populations. Findings of no impact arise from a study of anaemic preschool Indonesian children whose $\mathrm{Hb}$ concentration failed to rise following 2 months of receiving $20 \mathrm{mg}$ of vitamin C; however, lack of an adequate control group weakens the inference to be drawn from this study ${ }^{121}$. In Yugoslavia, $70 \mathrm{mg} \mathrm{day}^{-1}$ of ascorbic acid, given also for 2 months, failed to increase $\mathrm{Hb}$ or Hct among adolescent males, but the study population was not anaemic ${ }^{122}$.

Vitamin C may exert a measurable haematological effect in non-pregnant women. Among 32 non-anaemic, Nigerian women, receipt of $50 \mathrm{mg}$ or $100 \mathrm{mg} \mathrm{day}^{-1}$ of ascorbic acid significantly raised $\mathrm{Hb}$ concentration by 18 and $20 \mathrm{gl}^{-1}$, respectively, compared to a $4 \mathrm{gl}^{-1}$ decline in unsupplemented controls ${ }^{123}$. In a controlled dietary experiment, 11 American women aged 22-36 years underwent iron stores depletion through a low-iron diet and phlebotomy and then were placed on an iron-replete diet, supplemented with either placebo or $1500 \mathrm{mg}$ of ascorbic acid day ${ }^{-1}$ for 5.5 weeks ${ }^{124}$. Vitamin C recipients showed a slight, yet significant, rise in $\mathrm{Hb}$ concentration $\left(+0.5 \mathrm{gl}^{-1}\right)$ compared with the placebo group, whose mean $\mathrm{Hb}$ concentration declined by $c .3 \mathrm{gl}^{-1}$. Apparent iron absorption also significantly rose among vitamin C recipients (to $38 \%$ vs. $27 \%$ for placebos), who retained an additional $2.3 \mathrm{mg} \mathrm{day}^{-1}$ of iron from their diets. However, serum ferritin concentration remained unaffected by ascorbic acid.

Non-anaemic, iron-deficient women in Mexico were randomly assigned either lime juice containing $25 \mathrm{mg}$ ascorbic acid or a lime-flavoured placebo beverage to be consumed twice per day within 1 hour of meals ${ }^{125}$. After 6 months, gain in serum ferritin was consistently higher among supplemented women, representing an increase in iron absorption of up to $0.5 \mathrm{mg} \mathrm{day}^{-1}$. Hb concentration was unaffected by supplementation, possibly due to inadequacy of the daily $50 \mathrm{mg}$ vitamin $\mathrm{C}$ dose or to the initial absence of anaemia in subjects. However, negative findings emerged from a trial among anaemic and nonanaemic pregnant Filipina women, where the addition of $100-300 \mathrm{mg}$ of ascorbic acid to iron supplements daily for
16-18 weeks conferred no effect beyond that of iron alone in improving $\mathrm{Hb}$ concentration, Hct, serum iron or transferrin saturation by the time of delivery ${ }^{126}$.

Non-experimental studies support a modest effect of vitamin C. For example, a study among Indian vegetarians observed significant increases in $\mathrm{Hb}$ (by 8\%), serum iron (by 17\%) and serum ferritin (by 12\%) from baseline following receipt of $500 \mathrm{mg}$ of vitamin $\mathrm{C}$ after lunch and dinner for 2 months ${ }^{127}$. Providing well-nourished Turkish subjects with vitamin $\mathrm{C}(2 \mathrm{~g})$ daily was associated with rises in $\mathrm{Hb}$ concentration $\left(+11 \mathrm{gl}^{-1}\right)$ and serum iron $\left(+6 \mu \mathrm{mol} \mathrm{l}^{-1}\right)$ after 1 month; however, levels were comparable to baseline after a second month of supplementation ${ }^{128}$. Lack of concurrent comparison groups weaken the results of both of these studies.

In summary, evidence is lacking to support a clear role for vitamin $\mathrm{C}$ in improving the haematological status of pregnant women. Small studies to date do suggest that vitamin C may:

1. Improve absorption of non-haem iron, protect against oxidative damage and counteract the effects of iron absorption inhibitors.

2. Increase serum iron, ferritin and $\mathrm{Hb}$ concentrations among children and non-pregnant subjects.

\section{Vitamin E}

Vitamin E ( $\alpha$-tocopherol) is a lipid-soluble compound that functions in humans primarily as an antioxidant, scavenging highly reactive free radicals and protecting the polyunsaturated fatty acids (PUFAs) of cellular membranes from oxidative destruction. Nutritional deficiency of vitamin $\mathrm{E}$ is thought to be uncommon as it is widely distributed in foods, particularly vegetable and seed oils such as almond, sunflower, corn, soybean and wheat germ ${ }^{106}$. Susceptibility to deficiency is largely limited to premature and low birth weight newborns and to various pathological malabsorption syndromes such as cystic fibrosis, biliary atresia and abetalipoproteinaemia ${ }^{129}$.

Animal studies have observed the development of severe anaemia and morphological abnormalities of the bone marrow among primates on long-term vitamin Edeficient diets ${ }^{130,131}$. Treatment with vitamin $\mathrm{E}$ stimulated reticulocytosis and improved blood parameters among these animals ${ }^{132}$. Abnormal erythropoiesis, impaired iron metabolism and decreased erythrocyte survival times have also been observed in vitamin E-deficient animals ${ }^{130,133,134}$. In humans, vitamin $\mathrm{E}$ supplementation has been shown to increase the reticulocyte count ${ }^{135}$.

Preterm and low birth weight infants are born with low serum and tissue concentrations of vitamin $\mathrm{E}$, due in part to limited placental transport of tocopherols and to scarcity of storage adipose tissue ${ }^{129,136}$. Vitamin E deficiencyinduced anaemia in infants $6-12$ weeks of age has been characterized by red blood cell haemolysis, reticulocytosis, 


\begin{tabular}{|c|c|c|c|c|c|c|}
\hline Reference & $\begin{array}{l}\text { Subject population } \\
\text { (total sample size) }\end{array}$ & $\begin{array}{c}\text { Duration of } \\
\text { supplementation }\end{array}$ & Treatment groups and regimen & $\begin{array}{l}\text { Change in } \\
\text { mean haemoglobin } \\
\left(\mathrm{gl}^{-1}\right)\end{array}$ & $\begin{array}{l}\text { Change in } \\
\text { mean } \\
\text { haematocrit }\end{array}$ & Comments \\
\hline $\begin{array}{l}\text { Seshadri et al. } \\
\quad(1985)^{119}\end{array}$ & $\begin{array}{l}\text { India, } \\
\text { preschool children } \\
\text { (54) }\end{array}$ & 60 days & $\begin{array}{l}\text { Placebo } \\
200 \mathrm{mg} \text { VC/day }\end{array}$ & $\begin{array}{c}1.0 \\
19.2^{* *}\end{array}$ & Not reported & $\begin{array}{l}\text { Anaemic population } \\
\text { Small sample size }\end{array}$ \\
\hline $\begin{array}{l}\text { Mao \& Yao } \\
\quad(1992)^{120}\end{array}$ & $\begin{array}{l}\text { China, } \\
\text { preschool children } \\
3-5 \text { years } \\
(65)\end{array}$ & 8 weeks & $\begin{array}{l}\text { Placebo } \\
25 \mathrm{mg} \mathrm{VC/day} \\
50 \mathrm{mg} \mathrm{VC/day} \\
100 \mathrm{mg} \mathrm{VC/day} \\
150 \mathrm{mg} \mathrm{VC/day}\end{array}$ & $\begin{array}{l}11.4 \\
14.8 \\
14.5^{\star} \\
15.2^{\star} \\
16.9^{\star}\end{array}$ & $\begin{array}{l}0.014 \\
0.012 \\
0.014 \\
0.015 \\
0.026\end{array}$ & $\begin{array}{l}\text { Anaemic population } \\
\text { Blinded? }\end{array}$ \\
\hline $\begin{array}{l}\text { Angeles et al. } \\
\qquad(1993)^{121}\end{array}$ & $\begin{array}{l}\text { Indonesia, } \\
\text { preschool children } \\
2-5 \text { years } \\
\text { (80) }\end{array}$ & 8 weeks & $\begin{array}{l}20 \mathrm{mg} \mathrm{VC} / \text { day } \\
30 \mathrm{mg} \mathrm{Fe}+20 \mathrm{mg} \mathrm{VC} / \text { day }\end{array}$ & $\begin{array}{c}1.0 \\
10.0^{\star *}\end{array}$ & Not reported & $\begin{array}{l}\text { Anaemic population } \\
\text { Not designed to assess } \\
\text { the effect of VC } \\
\text { Control group } \\
\text { experienced greater } \\
\text { morbidity }\end{array}$ \\
\hline $\begin{array}{l}\text { Suboticanec- } \\
\text { Buzina et al. } \\
(1984)^{122}\end{array}$ & $\begin{array}{l}\text { Yugoslavia, } \\
\text { adolescent males } \\
11-13 \text { years } \\
(91)\end{array}$ & 2 months & $\begin{array}{l}2 \mathrm{mg} \text { riboflavin }+2 \mathrm{mg} \mathrm{B}_{6} / \text { day } \\
2 \mathrm{mg} \text { riboflavin }+2 \mathrm{mg} \mathrm{B}_{6}+70 \mathrm{mg} \mathrm{VC/day}\end{array}$ & $\begin{array}{r}1.0 \\
-1.0\end{array}$ & $\begin{array}{l}-0.007 \\
-0.002\end{array}$ & $\begin{array}{l}\text { Non-anaemic population } \\
\text { Blinded? } \\
\text { Randomized? }\end{array}$ \\
\hline $\begin{array}{l}\text { Ajayi \& Nnaji } \\
\qquad(1990)^{123}\end{array}$ & $\begin{array}{l}\text { Nigeria, } \\
\text { young adult women } \\
\text { (32) }\end{array}$ & 8 weeks & $\begin{array}{l}\text { No supplement } \\
50 \mathrm{mg} \mathrm{VC/day} \\
100 \mathrm{mg} \mathrm{VC/day}\end{array}$ & $\begin{array}{l}-4.3 \\
17.9^{\star *} \\
19.6^{\star *}\end{array}$ & $\begin{array}{l}-0.018 \\
0.057^{\star \star} \\
0.047^{\star \star}\end{array}$ & $\begin{array}{l}\text { Non-anaemic population } \\
\text { Blinded? } \\
\text { Small sample size }\end{array}$ \\
\hline $\begin{array}{l}\text { Hunt et al. } \\
\quad(1990)^{124}\end{array}$ & $\begin{array}{l}\text { USA, } \\
\text { young adult women } \\
\text { (11) }\end{array}$ & 5.5 weeks & $\begin{array}{l}\text { Placebo } \\
1500 \mathrm{mg} \text { VC/day }\end{array}$ & $\begin{array}{l}-3.0 \\
0.5^{\star}\end{array}$ & Not reported & $\begin{array}{l}\text { Controlled experimental } \\
\text { study }\end{array}$ \\
\hline $\begin{array}{l}\text { Garcia et al. } \\
\quad(1998)^{125}\end{array}$ & $\begin{array}{l}\text { Mexico, } \\
\text { adult women } \\
\text { (36) }\end{array}$ & 8 months & $\begin{array}{l}\text { Placebo } \\
\text { Lime juice with } 25 \mathrm{mg} \text { VC } 2 \times / \text { day }\end{array}$ & Not reported & Not reported & $\begin{array}{l}\text { Serum ferritin was } \\
\text { consistently higher } \\
\text { among VC- } \\
\text { supplemented group } \\
\text { VC increased Fe } \\
\text { absorption } \\
0.5 \text { mg day }^{-1}\end{array}$ \\
\hline $\begin{array}{l}\text { Kuizon et al. } \\
\quad(1979)^{126}\end{array}$ & $\begin{array}{l}\text { Philippines, } \\
\text { pregnant women } \\
(335)\end{array}$ & $\begin{array}{l}\text { 16-18 weeks } \\
\text { with } 7-8 \\
\text { month } \\
\text { follow-up }\end{array}$ & $\begin{array}{l}\text { Non-anaemic women: } \\
\text { Placebo } \\
65 \mathrm{mg} \mathrm{Fe} / \text { day } \\
100 \mathrm{mg} \mathrm{VC/day} \\
65 \mathrm{mg} \mathrm{Fe}+100 \mathrm{mg} \mathrm{VC/day} \\
\text { Anaemic women: } \\
\text { Placebo } \\
195 \mathrm{mg} \mathrm{Fe} / \text { day } \\
300 \mathrm{mg} \mathrm{VC} / \text { day } \\
195 \mathrm{mg} \mathrm{Fe}+300 \mathrm{mg} \mathrm{VC/day}\end{array}$ & $\begin{array}{r}-7.8 \\
3.9 \\
-2.9 \\
4.6 \\
\\
-4.0 \\
14.4 \\
-1.2 \\
11.1\end{array}$ & $\begin{array}{r}-0.016 \\
0.017 \\
-0.008 \\
0.017 \\
\\
0.002 \\
0.031 \\
0.003 \\
0.020\end{array}$ & \\
\hline
\end{tabular}


thrombocytosis and oedema that resolves promptly following vitamin $\mathrm{E}$ treatment ${ }^{137-141}$. However, in these landmark studies, improvement in $\mathrm{Hb}$ status following vitamin E supplementation occurred only among infants consuming a low tocopherol to PUFA ratio in their diet and receiving concurrent iron supplementation ${ }^{139,142-144}$. It was soon recognized that infant formula diets rich in PUFAs and low in $\alpha$-tocopherol, especially in the presence of oxidant compounds such as iron, potentiated the severity of deficiency and haemolytic anaemia. Promotion of early breast-feeding, modifications in modern infant formulas to lower PUFA and iron levels, and routine vitamin $\mathrm{E}$ supplementation have virtually eliminated severe vitamin E deficiency in premature infants ${ }^{106,145}$.

Randomized, placebo-controlled trials have examined the effect of vitamin $\mathrm{E}$ supplementation in preventing anaemia of prematurity among infants fed modern diets relatively low in PUFAs and iron (Table 8). Two, in Canada, among low birth weight infants, failed to improve $\mathrm{Hb}$ concentration, reticulocyte count or erythrocyte morphology after 6 weeks of supplementation with $16 \mathrm{mg}$ day $^{-1}$ of vitamin $E^{146-148}$. In England, preterm, low birth weight infants receiving either 5 or $15 \mathrm{mg} \mathrm{day}^{-1}$ of vitamin $\mathrm{E}$ had higher, albeit not significantly, $\mathrm{Hb}$ values than the control group at 10 weeks of age ${ }^{149}$. Similarly, a small Brazilian trial failed to find significant differences in $\mathrm{Hb}$ concentration, Hct or indicators of reticulocytosis among premature low birth weight infants treated for 6 weeks with iron, vitamin $\mathrm{E}$ or both ${ }^{150}$. The potential benefits of vitamin $\mathrm{E}$ supplementation may have been masked in these trials because the diets of premature, low birth weight infants commonly contain vitamin $\mathrm{E}$.

Non-experimental studies among anaemic, malnourished infants and children in Jordan ${ }^{151}$ and Thailand ${ }^{152}$ observed reticulocytosis and increases in Hb concentration and Hct following supplementation with oral vitamin E, but subsequent studies in India and Lebanon could not corroborate the response to vitamin E supplementation ${ }^{153,154}$. Lack of randomization and concurrent control groups leads to caution in interpreting the findings of these studies. However, a randomized, controlled trial among anaemic 1-3-year-old, protein-energy malnourished children in Thailand reported no additional improvements in $\mathrm{Hb}$ and reticulocyte counts from vitamin E given with iron relative to iron alone ${ }^{155}$.

To summarize, vitamin $\mathrm{E}$ is routinely given to preterm infants in developed countries to protect against the potential oxidative damage caused by iron supplementation. Under existing regimens to provide vitamin $\mathrm{E}$ to premature infants, additional supplementation with vitamin $\mathrm{E}$ has not further reduced the severity of anaemia of prematurity.

\section{Thiamine, niacin, pantothenic acid and vitamin $\mathbf{B}_{6}$}

Each of these four vitamins has been related to the development or treatment of anaemia during deficiency and supplementation, respectively, and warrants mention, although their public health significance with respect to anaemia is largely unknown. Thiamine-responsive megaloblastic anaemia, for example, is the product of a hereditary disorder of metabolism, part of a syndrome that is also characterized by diabetes mellitus and sensorineural deafness ${ }^{156}$. Niacin deficiency has produced macrocytic anaemia in some animal models, and normocytic anaemia has been reported among human patients with pellagra, but the anaemia cannot be specifically attributed to deficiency of niacin ${ }^{157,158}$. Animal studies have also observed anaemia following induced deficiency of pantothenic acid, but there has been only anecdotal evidence for the occurrence of pantothenic acid-responsive anaemia in humans ${ }^{159-161}$. No studies have been conducted to determine if these vitamins enhance erythropoiesis among malnourished populations.

Vitamin $\mathrm{B}_{6}$ (pyridoxine) deficiency can disturb haem synthesis and lead to normocytic, microcytic or sideroblastic anaemia (Fig. 1). Treatment of sideroblastic anaemia with vitamin $\mathrm{B}_{6}$ has resulted in the restored activity of erythroblastic $\delta$-aminolevulinic acid synthetase (ALAS), the rate-limiting enzyme in haem synthesis, followed by correction of the haematological abnormalities ${ }^{162,163}$. In Germany, after treating children hospitalized with iron deficiency anaemia for 8 days with iron plus vitamin $\mathrm{B}_{6}$, there was an apparent acceleration of haem synthesis, reflected in $\mathrm{Hb}$ concentrations that were higher than observed in children who received only iron (Table 9) ${ }^{164}$. Perhaps not surprisingly, supplementation of nonanaemic adolescents in Yugoslavia with $2 \mathrm{mg}$ of vitamin $\mathrm{B}_{6}$ daily for 2 months had no significant effect on $\mathrm{Hb}$ or Hct status relative to placebo ${ }^{104}$. Vitamin $\mathrm{B}_{6}$ may also inhibit sickling of erythrocytes in sickle-cell anaemia (SCA), possibly increasing erythrocyte counts, $\mathrm{Hb}$ concentrations and Hct among SCA patients ${ }^{165}$.

To recapitulate:

1. Thiamine, niacin and pantothenic acid have been related to human anaemia, but their public health significance with respect to anaemia is questionable.

2. Vitamin $B_{6}$ deficiency is rare, but treatment with $B_{6}$ may be effective in correcting the haematological abnormalities of sideroblastic anaemia.

\section{Multivitamin supplementation}

Studies previously cited have assessed the haematological effects of a single vitamin or small number of vitamins combined, with or without iron, but few trials have examined the haematopoietic impact of multivitamin supplementation. Most trials that have assessed the impact of multivitamin supplementation have used multivitamins with iron, and have not differentiated the effects of the vitamins from those obtained from iron alone. Table 10 summarizes a complex series of 
Table 8 Vitamin E supplementation trials that examined effects on haematological indicators

\begin{tabular}{|c|c|c|c|c|c|c|}
\hline Reference & $\begin{array}{l}\text { Subject population } \\
\text { (total sample size) }\end{array}$ & $\begin{array}{c}\text { Duration of } \\
\text { supplementation }\end{array}$ & Treatment groups and regimen & $\begin{array}{l}\text { Change in } \\
\text { mean haemoglobin } \\
\left(\mathrm{gl}^{-1}\right)\end{array}$ & $\begin{array}{c}\text { Change in } \\
\text { mean } \\
\text { haematocrit }\end{array}$ & Comments \\
\hline $\begin{array}{l}\text { Blanchette et al. } \\
(1980)^{146}\end{array}$ & $\begin{array}{l}\text { Canada, } \\
\text { low birth weight } \\
\text { infants (59) }\end{array}$ & 6 weeks & $\begin{array}{l}\text { Placebo } \\
16 \mathrm{mg} \mathrm{VE/day}\end{array}$ & Change not reported & Not reported & $\begin{array}{l}\text { No difference in } \\
\text { mean } \mathrm{Hb} \text { between } \\
\text { groups at } 6 \text { weeks }\end{array}$ \\
\hline $\begin{array}{l}\text { Zipursky et al. } \\
(1987)^{148}\end{array}$ & $\begin{array}{l}\text { Canada, } \\
\text { preterm infants } \\
<1500 \mathrm{~g}(178)\end{array}$ & 6 weeks & $\begin{array}{l}\text { Placebo } \\
16 \mathrm{mg} \text { VE/day }\end{array}$ & $\begin{array}{l}-59.0 \\
-69.0\end{array}$ & Not reported & Not VE deficient \\
\hline $\begin{array}{l}\text { Conway et al. } \\
(1986)^{149}\end{array}$ & $\begin{array}{l}\text { England, } \\
\text { preterm infants } \\
<1760 \mathrm{~g}(52)\end{array}$ & 10 weeks & $\begin{array}{l}\text { Placebo } \\
5 \mathrm{mg} \mathrm{VE/day} \\
15 \mathrm{mg} \mathrm{VE} / \text { day }\end{array}$ & $\begin{array}{l}-92.0 \\
-76.0 \\
-66.0 \\
\text { (median) }\end{array}$ & Not reported & \\
\hline $\begin{array}{l}\text { Ferlin et al. } \\
\qquad(1998)^{150}\end{array}$ & $\begin{array}{l}\text { Brazil, } \\
\text { preterm infants } \\
<1600 \mathrm{~g}(40)\end{array}$ & 6 weeks & $\begin{array}{l}\text { Placebo } \\
4 \mathrm{mg} / \mathrm{kg} / \text { day } \mathrm{Fe} \\
4 \mathrm{mg} / \mathrm{kg} / \text { day } \mathrm{Fe}+16 \mathrm{mg} \mathrm{VE} / \text { day } \\
16 \mathrm{mg} \mathrm{VE} / \text { day }\end{array}$ & $\begin{array}{l}-105.0 \\
-84.0 \\
-94.0 \\
-81.0 \\
\text { (median) }\end{array}$ & $\begin{array}{l}-0.292 \\
-0.225 \\
-0.222 \\
-0.235\end{array}$ & Blinded? \\
\hline $\begin{array}{l}\text { Kulapongs } \\
(1975)^{155}\end{array}$ & $\begin{array}{l}\text { Thailand, } \\
\text { children } 1-3 \text { years } \\
\text { with PEM (70) }\end{array}$ & 12 weeks & $\begin{array}{l}\text { Placebo } \\
10 \mathrm{mg} / \mathrm{kg} / \mathrm{day} \mathrm{VE}+3 \mathrm{mg} / \mathrm{kg} / \text { day Fe for } 12 \text { weeks } \\
\text { VE alone for } 6 \text { weeks followed by VE }+ \text { Fe for } 6 \text { weeks } \\
\text { Fe alone for } 6 \text { weeks followed by VE }+ \text { Fe for } 6 \text { weeks }\end{array}$ & $\begin{array}{l}12.0 \\
38.0 \\
23.0 \\
23.5\end{array}$ & Not reported & $\begin{array}{l}\mathrm{Hb} \text { and reticulocyte } \\
\text { responses occurred } \\
\text { only after Fe was } \\
\text { given }\end{array}$ \\
\hline
\end{tabular}

PEM, protein-energy malnutrition; VE, vitamin $\mathrm{E}$. 


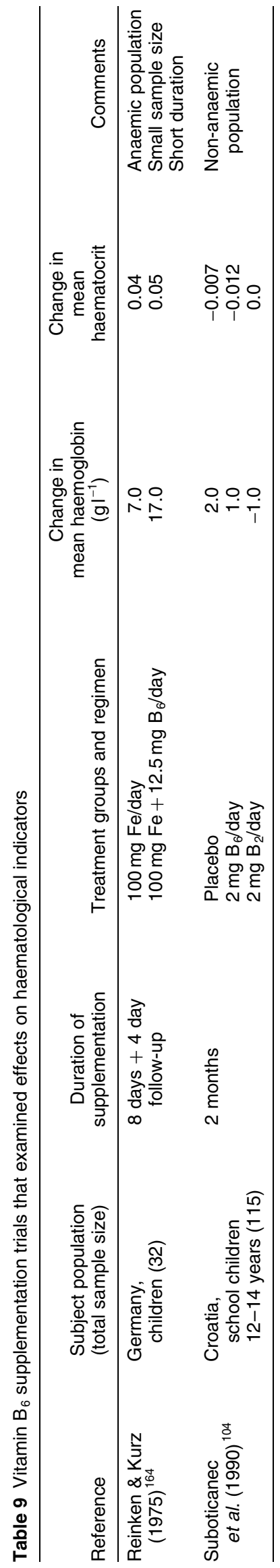

multivitamin supplementation trials that have assessed outcomes relating to anaemia.

In Peru, 10 weeks of daily multivitamin supplement use (containing thiamin, riboflavin, $\mathrm{B}_{12}$, folate and niacin) added to iron had no effect over iron alone on $\mathrm{Hb}$ levels of children aged $7-13$ years ${ }^{166}$. Among preschool anaemic children in Germany, however, a combination of iron, folate, vitamin $\mathrm{C}$, riboflavin, $\mathrm{B}_{6}$ and $\mathrm{B}_{12}$ for just 9 days raised mean $\mathrm{Hb}$ concentration $5 \mathrm{gl}^{-1}$ above that of children receiving iron alone ${ }^{167}$. Russian school children were also reported to have shown significant increases in $\mathrm{Hb}$ concentration and lower morbidity rates during 5-7 months of multivitamin supplementation (composition not described) compared to unsupplemented controls ${ }^{168}$.

Significant increases in serum iron and aerobic capacity were observed, compared with controls, in non-anaemic Yugoslav adolescents given daily ascorbic acid, riboflavin and $\mathrm{B}_{6}$ for 3 months ${ }^{169}$. However, supplementation induced no significant changes in $\mathrm{Hb}$ or Hct. In India, among children aged 6 months to 6 years, $100 \%$ of the children receiving only folate and $\mathrm{B}_{12}$ for 12 weeks experienced some rise in $\mathrm{Hb}$ concentration, compared to $87 \%$ receiving only vitamins A and D, 92\% receiving $40 \mathrm{mg}$ of iron alone twice weekly, and $37 \%$ receiving placebo ${ }^{170}$.

Among HIV-1-infected pregnant women in Tanzania, those taking multivitamins (either with or without vitamin A) had significantly higher increases in mean $\mathrm{Hb}$ concentration at 6 weeks postpartum than did women not taking multivitamins (13 vs. $\left.6 \mathrm{gl}^{-1}\right)^{37}$. All of the women received $120 \mathrm{mg} \mathrm{day}^{-1}$ of iron, $5 \mathrm{mg} \mathrm{day}^{-1}$ of folic acid and a weekly antimalarial, thus explaining the $\mathrm{Hb}$ increase in those not receiving the multivitamins.

Other multivitamin studies have demonstrated haematological improvements, but have not been designed to isolate the haematological effects of vitamins from iron. In the Gambia, a seasonal decline in $\mathrm{Hb}$ due to malaria and hookworm among vitamin-deficient prepubescent children appeared to be staunched somewhat by a multivitamin of thiamin, riboflavin, ascorbic acid and iron ${ }^{171}$. In China, a daily micronutrient-fortified weaning biscuit maintained the mean $\mathrm{Hb}$ concentration of infants aged 6-13 months, while $\mathrm{Hb}$ declined significantly $\left(-8 \mathrm{gl}^{-1}\right)$ among infants receiving unfortified biscuits ${ }^{172}$. Among predominantly non-anaemic South African school children, biscuits fortified with iron, iodine and vitamin A along with a vitamin C-enriched drink significantly improved $\mathrm{Hb}$ concentration $3 \mathrm{gl}^{-1}$ more than supplementation with unfortified biscuits and placebo drink after 12 months ${ }^{173}$.

Among 6-24-month-old Vietnamese children, a daily multivitamin (iron, vitamin $\mathrm{A}$, vitamin $\mathrm{C}$ and zinc) or a higher-dose weekly multivitamin, produced highly significant increases in mean $\mathrm{Hb}$ of 16 and $13 \mathrm{gl}^{-1}$, respectively, and a reduction in the prevalence of anaemia from $50 \%$ to $<10 \%$, compared to no change in $\mathrm{Hb}$ in the placebo group $^{174}$. In Indonesia, among non-pregnant adolescent girls, 12 weeks of multivitamins containing either lower 
Table 10 Multivitamin supplementation trials that examined effects on haematological indicators

\begin{tabular}{|c|c|c|c|c|c|c|c|}
\hline Reference & $\begin{array}{l}\text { Subject population } \\
\text { (total sample size) }\end{array}$ & $\begin{array}{c}\text { Duration of } \\
\text { supplementation }\end{array}$ & $\begin{array}{l}\text { Composition of } \\
\text { multivitamin }\end{array}$ & Treatment groups and regimen & $\begin{array}{l}\text { Change in } \\
\text { mean haemoglobin } \\
\left(\mathrm{g} \mathrm{I}^{-1}\right)\end{array}$ & $\begin{array}{l}\text { Change in } \\
\text { mean } \\
\text { haematocrit }\end{array}$ & Comments \\
\hline $\begin{array}{l}\text { Bradfield et al. } \\
\quad(1968)^{166}\end{array}$ & $\begin{array}{l}\text { Peru, } \\
\text { school children } \\
7-13 \text { years }(156)\end{array}$ & 10 weeks & $\begin{array}{l}0.5 \mathrm{mg} \text { thiamine } \\
1 \mathrm{mg} \text { riboflavin } \\
3 \mu \mathrm{g} \mathrm{B}_{12} \\
0.2 \mathrm{mg} \text { folic acid } \\
5 \mathrm{mg} \text { niacin }\end{array}$ & $\begin{array}{l}\text { Placebo } \\
5 \mathrm{mg} \mathrm{Fe} / \text { day } \\
\text { Multivitamin }+5 \mathrm{mg} \mathrm{Fe} / \text { day } \\
\text { Antihelminth }+ \text { placebo } \\
\text { Antihelminth }+5 \mathrm{mg} \mathrm{Fe} / \text { day } \\
\text { Antihelminth + multivitamin }+5 \mathrm{mg} \mathrm{Fe} / \text { day }\end{array}$ & $\begin{array}{r}-12.0 \\
3.0 \\
3.0 \\
13.0^{\star} \\
5.0^{\star} \\
11.0^{\star}\end{array}$ & $\begin{array}{r}-0.01 \\
0.01 \\
0.02 \\
0.02 \\
0.03^{\star} \\
0.05^{\star}\end{array}$ & $\begin{array}{l}34 \% \text { of population } \\
\text { anaemic at baseline }\end{array}$ \\
\hline $\begin{array}{l}\text { Reinken \& Kurz } \\
(1978)^{167}\end{array}$ & $\begin{array}{l}\text { Germany, } \\
\text { preschool children } \\
(28)\end{array}$ & 9 days & $\begin{array}{l}104.4 \mathrm{mg} \mathrm{Fe} \\
0.9 \mathrm{mg} \text { folic acid } \\
15 \mu \mathrm{g} \mathrm{B}_{12} \\
225 \mathrm{mg} \mathrm{VC} \\
4.5 \mathrm{mg} \text { riboflavin } \\
12 \mathrm{mg} \mathrm{B}_{6}\end{array}$ & $\begin{array}{l}104.4 \mathrm{mg} \mathrm{Fe} / \text { day } \\
\text { Multivitamin/day }\end{array}$ & $\begin{array}{r}9.0 \\
14.0\end{array}$ & $\begin{array}{l}0.026 \\
0.042\end{array}$ & \\
\hline $\begin{array}{l}\text { Buzina et al. } \\
\quad(1982)^{169}\end{array}$ & $\begin{array}{l}\text { Yugoslavia, } \\
\text { male school } \\
\text { children 12-15 } \\
\text { years (201) }\end{array}$ & 3 months & & $\begin{array}{l}\text { No supplement } \\
70 \mathrm{mg} \text { VC }+2 \mathrm{mg} \text { riboflavin }+2 \mathrm{mg} \mathrm{B}_{6} / \text { day }\end{array}$ & $\begin{array}{r}-2.0 \\
1.0\end{array}$ & $\begin{array}{l}-0.004 \\
0.0\end{array}$ & $\begin{array}{l}\text { Non-anaemic population } \\
\text { Not blinded } \\
\text { Randomized? }\end{array}$ \\
\hline $\begin{array}{l}\text { Das et al. } \\
\qquad(1984)^{170}\end{array}$ & $\begin{array}{l}\text { India, } \\
\text { preschool children } \\
0.5-6 \text { years }(175)\end{array}$ & 12 weeks & & $\begin{array}{l}\text { Placebo } \\
360 \mu \mathrm{g} \mathrm{RE} \mathrm{VA}+200 \text { IU VD } 5 \times / \text { week } \\
1.4 \mu \mathrm{g} \mathrm{B}_{12}+140 \mu \mathrm{g} \text { folic acid } 5 \times / \text { week } \\
5 \mathrm{mg} \mathrm{Fe} 5 \times / \text { week } \\
10 \mathrm{mg} \mathrm{Fe} 5 \times / \text { week } \\
20 \mathrm{mg} \mathrm{Fe} 2 \times / \text { week } \\
40 \mathrm{mg} \mathrm{Fe} 2 \times / \text { week } \\
20 \mathrm{mg} \mathrm{Fe} 1 \times / \text { week } \\
40 \mathrm{mg} \mathrm{Fe} 1 \times / \text { week }\end{array}$ & $\begin{array}{l}2.9 \\
9.9^{\star} \\
20.8^{\star \star} \\
2.5 \\
3.2 \\
8.4^{\star} \\
14.8^{\star \star} \\
8.2^{\star} \\
8.4^{\star}\end{array}$ & Not reported & \\
\hline $\begin{array}{l}\text { Fawzi et al. } \\
\qquad(1998)^{37}\end{array}$ & $\begin{array}{l}\text { Tanzania, } \\
\text { HIV+ pregnant } \\
\text { women (1075) }\end{array}$ & $\begin{array}{l}\text { 2nd trimester } \\
\text { enrolment to } \\
\text { delivery } \\
\text { (13-28 weeks) }\end{array}$ & $\begin{array}{l}20 \mathrm{mg} \mathrm{B}_{1} \\
20 \mathrm{mg} \text { riboflavin } \\
25 \mathrm{mg} \mathrm{B} \mathrm{B}_{6} \\
100 \mathrm{mg} \text { niacin } \\
50 \mu \mathrm{g} \mathrm{B}_{12} \\
500 \mathrm{mg} \mathrm{VC} \\
30 \mathrm{mg} \mathrm{VE} \\
0.8 \mathrm{mg} \text { folic acid }\end{array}$ & $\begin{array}{l}\text { Placebo } \\
6500 \mu \mathrm{g} \text { RE VA/day } \\
6500 \mu \mathrm{g} \text { RE VA + multivitamin/day } \\
\text { Multivitamin/day }\end{array}$ & $\begin{array}{l}\text { Not reported per } \\
\text { group }\end{array}$ & Not reported & $\begin{array}{l}\text { Change in mean } \mathrm{Hb} \text { at } \\
6 \text { weeks postpartum: } \\
\text { multivitamins: } 1.3^{\star} ; \\
\text { no multivitamins: } 0.6\end{array}$ \\
\hline
\end{tabular}




\begin{tabular}{|c|c|c|c|c|c|c|c|}
\hline $\begin{array}{l}\text { Powers et al. } \\
\qquad(1985)^{171}\end{array}$ & $\begin{array}{l}\text { The Gambia, } \\
\text { school children } \\
11-14.5 \text { years } \\
(40)\end{array}$ & 10 weeks & $\begin{array}{l}60 \mathrm{mg} \mathrm{Fe} \\
23 \mathrm{mg} \text { thiamin } \\
23 \mathrm{mg} \text { riboflavin } \\
750 \mathrm{mg} \mathrm{VC}\end{array}$ & $\begin{array}{l}\text { Placebo } \\
\text { Multivitamin/week }\end{array}$ & $\begin{array}{l}-6.4 \\
-1.8\end{array}$ & $\begin{array}{l}-0.077 \\
-0.041\end{array}$ & $\begin{array}{l}27.5 \% \text { of population } \\
\text { anaemic at baseline }\end{array}$ \\
\hline $\begin{array}{l}\text { Liu et al. } \\
\qquad(1993)^{172}\end{array}$ & $\begin{array}{l}\text { China, } \\
\text { infants } 6-13 \\
\text { months (226) }\end{array}$ & 3 months & $\begin{array}{l}5 \mathrm{mg} \mathrm{Fe} \\
25 \mu \mathrm{g} \text { folic acid } \\
0.3 \mu \mathrm{g} \mathrm{B} \\
0.2 \mathrm{mg} \\
\text { Riboflavin } \\
224 \mu \mathrm{g} \mathrm{VA} \\
0.15 \mu \mathrm{g} \text { thiamin } \\
2.5 \mathrm{mg} \text { niacin } \\
3.0 \mathrm{mg} \text { zinc } \\
300 \mathrm{mg} \text { calcium }\end{array}$ & $\begin{array}{l}\text { Unfortified weaning biscuit/day } \\
\text { Vitamin-fortified weaning biscuit/day }\end{array}$ & $\begin{array}{l}-7.9 \\
-0.8^{* *}\end{array}$ & Not reported & Double blinded? \\
\hline $\begin{array}{l}\text { Van Stuijvenberg } \\
\text { et al. }(1999)^{173}\end{array}$ & $\begin{array}{l}\text { South Africa, } \\
\text { school children } \\
6-11 \text { years }(252)\end{array}$ & 43 weeks & $\begin{array}{l}\text { Fortified biscuit: } \\
5 \mathrm{mg} \mathrm{Fe} \\
2.1 \mathrm{mg} \mathrm{VA} \\
60 \mu \mathrm{g} \text { iodine }\end{array}$ & $\begin{array}{l}\text { Unfortified biscuit + placebo drink } 5 \times / \text { week } \\
\text { Fortified biscuit }+90 \mathrm{mg} \text { VC drink } 5 \times / \text { week }\end{array}$ & $\begin{array}{c}1.0 \\
4.0^{\star \star} \\
\text { (median) }\end{array}$ & $\begin{array}{l}0.0 \\
0.008^{\star} \\
\text { (median) }\end{array}$ & $\begin{array}{l}25-30 \% \text { prevalence of } \\
\text { anaemia at baseline } \\
40 \% \text { prevalence of } \\
\text { low VA status }\end{array}$ \\
\hline $\begin{array}{l}\text { Thu et al. } \\
(1999)^{174}\end{array}$ & $\begin{array}{l}\text { Vietnam, } \\
\text { preschool children } \\
6-24 \text { months (163) }\end{array}$ & 3 months & $\begin{array}{l}\text { Daily vitamin: } \\
333 \mu \mathrm{g} \mathrm{VA} \\
8 \mathrm{mg} \mathrm{Fe} \\
5 \mathrm{mg} \mathrm{Zn} \\
20 \mathrm{mg} \mathrm{VC} \\
\text { Weekly vitamin: } \\
1700 \mu \mathrm{g} \mathrm{VA} \\
20 \mathrm{mg} \mathrm{Fe} \\
17 \mathrm{mg} \mathrm{Zn} \\
20 \mathrm{mg} \mathrm{VC}\end{array}$ & $\begin{array}{l}\text { Placebo } \\
\text { Daily multivitamin } 5 \times / \text { week } \\
\text { Weekly multivitamin } 1 \times / \text { week }\end{array}$ & $\begin{array}{l}-0.5 \\
15.5^{\star \star} \\
13.2^{\star \star}\end{array}$ & Not reported & $\begin{array}{l}41-48 \% \text { of population } \\
\text { anaemic at baseline }\end{array}$ \\
\hline $\begin{array}{l}\text { Angeles-Agdeppa } \\
\text { et al. }(1997)^{175}\end{array}$ & $\begin{array}{l}\text { Indonesia, } \\
\text { adolescent girls } \\
\text { (363) }\end{array}$ & 3 months & $\begin{array}{l}\text { Composition 'A': } \\
750 \mu \mathrm{g} \text { VA } \\
250 \mu \mathrm{g} \text { folic acid } \\
60 \mathrm{mg} \text { VC } \\
\text { Composition 'B': } \\
6000 \mu \mathrm{g} \text { VA } \\
500 \mu \mathrm{g} \text { folic acid } \\
60 \mathrm{mg} \text { VC }\end{array}$ & $\begin{array}{l}\text { Placebo } \\
60 \mathrm{mg} \mathrm{Fe}+1 \text { 'A'/day } \\
60 \mathrm{mg} \mathrm{Fe}+1 \text { 'B'/week } \\
120 \mathrm{mg} \mathrm{Fe}+1 \text { 'B'/week }\end{array}$ & $\begin{array}{l}-2.8 \\
3.3^{\star \star} \\
5.6^{\star \star} \\
3.7^{\star \star}\end{array}$ & Not reported & $\begin{array}{l}17.4 \% \text { of population } \\
\text { anaemic at baseline }\end{array}$ \\
\hline
\end{tabular}

VA, vitamin $A ;$ VC, vitamin C; VD, vitamin D; VE, vitamin $E$.

${ }^{*} P<0.05$ relative to control group.
${ }^{* \star} P<0.01$ relative to control group. 
daily doses or higher weekly doses of vitamin A, vitamin C, folate and iron led to significant increases in mean $\mathrm{Hb}$ $\left(3.3-5.6 \mathrm{~g} \mathrm{l}^{-1}\right)$ and ferritin levels $\left(14.2-27.2 \mu \mathrm{gl}^{-1}\right)$ relative to a placebo group $\left(-2.8 \mathrm{gl}^{-1}\right.$ and $-4.6 \mu \mathrm{gl}^{-1}$, respectively) ${ }^{175}$. A study in New Jersey examined the effects of prenatal multivitamin supplement (containing folic acid, calcium, zinc and iron) use by low income pregnant women on birth outcomes and blood ferritin, zinc and folate levels ( $\mathrm{Hb}$ and $\mathrm{Hct}$ were not assessed) ${ }^{176}$. By 28 weeks' gestation, women who had used the multivitamins during their first or second trimesters had higher serum ferritin values relative to non-users, indicating an improvement in iron stores.

In summary, the prevention and control of nutritional anaemia in many populations will probably require the use of multivitamin supplements. However:

1. Most efficacy studies of multivitamin supplement use to date have not differentiated the haematological effects of vitamins from those achieved with supplemental iron alone. 2. Thus, there is presently insufficient data among pregnant women, adolescent girls and children to assess the haematological benefit of multivitamin supplementation, independent of the iron effect.

\section{Conclusions}

A large number of studies have evaluated the effects of single or multivitamin use on various health and nutritional outcomes in different population settings, but most have not been designed to adequately assess vitamin impact on $\mathrm{Hb}$, Hct and other haematological measures. While consistency of effect can sometimes be gleaned for a particular nutrient or group of vitamins across diverse population groups, discrepant findings tend more to be the rule than the exception within and between demographic, life-stage and geographic classes of subjects. Where consistency in effect exists, mechanisms at times can be invoked; discordance in effect between different groups of individuals leaves open a search for mechanisms both to explain the haematological effect and its variability.

The roles of most vitamins in controlling anaemia among high-risk populations have yet to be adequately explored. Among preschool-aged children, there is evidence that vitamins $\mathrm{A}$ and $\mathrm{C}$ can effectively raise haemoglobin levels, but no studies have been done to assess folic acid, vitamin $\mathrm{B}_{12}$, riboflavin or other vitamins. Among school-aged children, vitamin A has been effective, and there is some evidence that riboflavin can improve haematological status, but no large folic acid, vitamin $\mathrm{C}, \mathrm{E}$ or $\mathrm{B}_{6}$ studies have been conducted. Among pregnant women, evidence regarding the effectiveness of folic acid is still conflicting; no studies have isolated the effects of vitamin $\mathrm{B}_{12}$; evidence regarding riboflavin remains insufficient; and studies are needed to demonstrate the effects of vitamins $\mathrm{C}, \mathrm{E}_{\mathrm{O}}$ or $\mathrm{B}_{6}$ in gravid women. Among non-pregnant women of reproductive age, vitamins A and $\mathrm{C}$ have been effective in improving haematological status; folic acid and riboflavin have been shown to be effective in small trials, but no studies have assessed the haematological effects of vitamins $\mathrm{B}_{12}, \mathrm{~B}_{6}$ or E. Perhaps most importantly, though, is a need for multivitamin supplementation studies among each of these populations that isolate the effects of vitamins from the haematological effects of iron supplementation. Further, there is a need for studies to compare the effectiveness of different vitamin combinations in order to examine possible interactions or enhancement of effects.

\section{Acknowledgements}

We thank Hector Cori, Jaime Piza and Roche Pharmaceutical Company for their interest and financial support in the production of this review. Additional support from The Office of Health and Nutrition, US Agency for International Development, Washington, DC under Cooperative Agreement HRN-A-00-97-00015-00 with The Center for Human Nutrition, Johns Hopkins School of Public Health, Baltimore, MD is gratefully acknowledged. This review was prepared as an activity within the Johns HopkinsRoche Sight In Life Institute, Baltimore, MD, USA.

\section{References}

1 ACC/SCN. Second Report on the World Nutrition Situation. Vol. 1. Global and Regional Results. Geneva: Administrative Committee on Coordination/Subcommittee on Nutrition, 1992.

2 WHO/UNICEF/UNU. Iron Deficiency: Indicators for Assessment and Strategies for Prevention. Geneva: World Health Organization, 1997.

3 Lee GR. The anemia of chronic disease. Semin. Hematol. 1983; 20: 61-80.

4 Fairbanks VF. Iron in medicine and nutrition. In: Shils ME, Olson JA, Shike M, eds. Modern Nutrition in Health and Disease. Philadelphia: Lea and Febiger, 1994; 185-213.

5 Viteri FE. Iron supplementation for the control of iron deficiency in populations at risk. Nutr. Rev. 1997; 55: 195209.

6 DeMaeyer E, Adiels-Tegman M. The prevalence of anaemia in the world. Rapp. Trimest. Statist. Sanit. Mond. 1985; 38: 302-16.

7 International Nutritional Anemia Consultative Group (INACG). Iron Deficiency in Women. Washington, DC: The Nutrition Foundation, 1981.

8 Rossiter CE. Maternal mortality. Br. J. Obstet. Gynaecol. 1985; 5 (Suppl.): 100-15.

9 Dallman PR. Iron. In: Brown ML, ed. Present Knowledge in Nutrition. Washington, DC: International Life Sciences Institute/Nutrition Foundation, 1990; 241-50.

10 Christian P. Antenatal iron supplementation as a child survival strategy. Am. J. Clin. Nutr. 1998; 68: 403-4.

11 Sommer A. Nutritional Blindness. New York: Oxford University Press, 1982

12 Humphrey JH, West KP, Sommer A. Vitamin A deficiency and attributable mortality among under-5-year-olds. Bull. World Health Org. 1992; 70: 225-32.

13 Sommer A, West KP. Vitamin A Deficiency: Health, Survival and Vision. New York: Oxford University Press, 1996. 
14 WHO. Indicators for Assessing Vitamin A Deficiency and their Application in Monitoring and Evaluating Intervention Programmes. Geneva: World Health Organization, 1996.

15 Beaton GH, Martorell R, L'Abbe KA, et al. Effectiveness of Vitamin A Supplementation in the Control of Young Child Morbidity and Mortality in Developing Countries. Final Report to CIDA. Toronto: University of Toronto, 1992.

16 Fawzi Ww, Chameres TC, Herrera MG, Mosteller F. Vitamin A supplementation and child mortality. JAMA 1993; 269: 898-903.

17 Glasziou PP, Mackerras DEM. Vitamin A supplementation in infectious diseases: a meta-analysis. BMJ 1993; 306: 36670.

18 Findlay GM, Mackenzie RD. The bone marrow in deficiency diseases. J. Pathol. 1922; 25: 402-3.

19 Wolbach SB, Howe PR. Tissue changes following deprivation of fat-soluble A vitamin. J. Exp. Med. 1925; 42: 753-77.

20 Koessler KK, Maurer S, Loughlin R. The relation of anemia, primary and secondary, to vitamin A deficiency. JAMA 1926; 87: 476-82.

21 Sure B, Kik MC, Walker DJ. The effect of avitaminosis on hematopoietic function. I. Vitamin A deficiency. J. Biol. Chem. 1929; 83: 375-85.

22 Blackfan KD, Wolbach SB. Vitamin A deficiency in infants: a clinical and pathological study. J. Pediatr. 1933; 3: 679706.

23 Mejia LA, Hodges RE, Arroyave G, Viteri F, Torun B. Vitamin A deficiency and anemia in Central American children. Am. J. Clin. Nutr. 1977; 30: 1175-84.

24 Wolde-Gebriel Z, Gebru H, Fisseha T, West CE. Severe vitamin A deficiency in a rural village in the Hararge region of Ethiopia. Eur. J. Clin. Nutr. 1993; 47: 104-14.

25 Ahmed F, Barua S, Mohiduzzaman M, et al. Interactions between growth and nutrient status in school-age children of urban Bangladesh. Am. J. Clin. Nutr. 1993; 58: 334-8.

26 Bloem MW, Wedel M, Egger RJ, et al. Iron metabolism and vitamin A deficiency in children in northeast Thailand. Am. J. Clin. Nutr. 1989; 50: 332-8.

27 Mohanram M, Kulkarni KA, Reddy V. Hematological studies in vitamin A deficient children. Int. J. Vitam. Nutr. Res. 1977; 47: 389-93.

28 Hodges RE, Sauberlich HE, Canham JE, et al. Hematopoietic studies in vitamin A deficiency. Am. J. Clin. Nutr. 1978; 31: 876-85.

29 Mejia LA, Arroyave G. The effect of vitamin A fortification of sugar on iron metabolism in preschool children in Guatemala. Am. J. Clin. Nutr. 1982; 36: 87-93.

30 Mejia LA. Vitamin A deficiency as a factor in nutritional anemia. Int. J. Vitam. Nutr. Res. 1985; 27: 75-84.

31 Muhilal, Permeisih D, Idjradinata YR, Muherdiyantiningsih, Karyadi D. Vitamin A-fortified monosodium glutamate and health, growth, and survival of children: a controlled field trial. Am. J. Clin. Nutr. 1988; 48: 1271-6.

32 Mejia LA, Chew F. Hematological effect of supplementing anemic children with vitamin A alone and in combination with iron. Am. J. Clin. Nutr. 1988; 48: 595-600.

33 Smith JC, Makdani D, Hegar A, Rao D, Douglass LW. Vitamin A and zinc supplementation of preschool children. J. Am. Coll. Nutr. 1999; 18: 213-22.

34 Panth M, Shatrugna V, Yasodhara P, Sivakumar B. Effect of vitamin A supplementation on haemoglobin and vitamin A levels during pregnancy. Br.J. Nutr. 1990; 64: 351-8.

35 Suharno D, West CE, Muhilal, Karyadi D, Hautvast JGAJ. Supplementation with vitamin A and iron for nutritional anaemia in pregnant women in West Java, Indonesia. Lancet 1993; 342: 1325-8.

36 Shatrugna V, Raman L, Uma K, Sujatha T. Interaction between vitamin A and iron: effects of supplements in pregnancy. Int. J. Vitam. Nutr. Res. 1997; 67: 145-8.
37 Fawzi WW, Msamanga GI, Spiegelman D, et al. Randomised trial of effects of vitamin supplements on pregnancy outcomes and T cell counts in HIV-1-infected women in Tanzania. Lancet 1998; 351: 1477-82.

38 Mahomed K, Hytten F. Iron and folate supplementation in pregnancy. In: Chalmers I, ed. Effective Care in Pregnancy and Childbirth. London: Oxford University Press, 1989.

39 Bloem MW, Wedel M, van Agtmaal EJ, Speek AJ, Saowakontha S, Schreurs WHP. Vitamin A intervention: short-term effects of a single, oral, massive dose on iron metabolism. Am. J. Clin. Nutr. 1990; 51: 76-9.

40 Semba RD, Muhilal, West KP, et al. Impact of vitamin A supplementation on hematological indicators of iron metabolism and protein status in children. Nutr. Res. 1992; 12: 469-78.

41 Chawla PK, Puri R. Impact of nutritional supplements on hematological profile of pregnant women. Indian J. Pediatr. 1995; 32: 876-80.

42 Kolsteren P, Rahman SR, Hilderbrand K, Diniz A. Treatment for iron deficiency anaemia with a combined supplementation of iron, vitamin A, and zinc in women of Dinajpur, Bangladesh. Eur. J. Clin. Nutr. 1999; 53: 102-6.

43 Christian P, West KP Jr. Interactions between zinc and vitamin A: an update. Am. J. Clin. Nutr. 1998; 68 (Suppl. 2): S435-41.

44 Stoltzfus RJ, Dreyfuss M, Shrestha JB, Khatry SK, Schulze $\mathrm{K}$, West KP. Effect of maternal vitamin A or carotene supplementation on iron-deficiency anemia in Nepalese pregnant women, post-partum mothers, and infants. In Report of the XVIII International Vitamin A Consultative Group Meeting, Cairo, Egypt. Washington, DC: International Life Science Institute Research Foundation, 1997; 86.

45 Koeffler HP, Amatruda TT. The effect of retinoids on haemopoiesis - clinical and laboratory studies. In: Pitman, ed. Retinoids, Differentiation, and Disease. London: Ciba Foundation Symposium, 1985; 252-73.

46 Amatruda TT, Koeffler HP. Retinoids and cells of the hematopoietic system. In: Sherman MI, ed. Retinoids and Cell Differentiation. Boca Raton, Florida: CRC Press, 1986; 80-103.

47 Jelkmann W, Pagel H, Hellwig T, Fandrey J. Effects of antioxidant vitamins on renal and hepatic erythropoietin production. Kidney Int. 1997; 51: 497-501.

48 Mejia LA, Hodges RE, Rucker RB. Role of vitamin A in the absorption, retention, and distribution of iron in the rat. J. Nutr. 1979; 109: 129-37.

49 Semba RD. Vitamin A, immunity, and infection. Clin Infect. Dis. 1994; 19: 489-99.

50 Bloem MW. Interdependence of vitamin A and iron: an important association for programmes of anaemia control. Proc. Nutr. Soc. 1995; 54: 501-8.

51 Garcia-Casal MN, Layrisse M, Solano L, et al. Vitamin A and $\beta$-carotene can improve nonheme iron absorption from rice, wheat, and corn by humans. J. Nutr. 1997; 128: 646-50.

52 Layrisse M, Garcia-Casal MN, Solano L, et al. Vitamin A reduces the inhibition of iron absorption by phytates and polyphenols. Food Nutr. Bull. 1998; 19: 3-5.

53 Gallagher PG, Ehrenkranz RA. Nutritional anemias in infancy. Clin. Perinatol. 1995; 22: 671-92.

54 Myhre E. Studies on megaloblasts in vitro. Scand. J. Clin. Lab. Invest. 1964; 16: 307.

55 Rondanelli EG, Gorini P, Magliulo E, Fiori GP. Differences in proliferative activity between normoblasts and pernicious anemia megaloblasts. Blood 1964; 24: 542.

56 Steinberg SE, Fonda S, Campbell CL, Hillman RS. Cellular abnormalities of folate deficiency. Br. J. Haematol. 1983; 54: 605 .

57 Hughes-Jones NC, Wickramasinghe SN. Lecture Notes on Haematology. Oxford: Blackwell Science, 1996.

58 Strieff RR, Little AB. Folic acid deficiency in pregnancy. N. Engl. J. Med. 1967; 276: 776. 
59 Blot I, Papierhik F, Kaltwasser JP, et al. Influence of routine administration of folic acid and iron during pregnancy. Gynecol. Obstet. Invest. 1981; 12: 294.

60 Herbert V, Das KC. Folic acid and vitamin B12. In: Shils ME, Olson JA, Shike M, eds. Modern Nutrition in Health and Disease. Philadelphia: Lea and Febiger, 1994; 402-25.

61 Burland WL, Simpson K, Lord J. Response of low birthweight infants to treatment with folic acid. Arch. Dis. Child. 1971; 46: 189-94.

62 Strelling MK, Blackledge DG, Goodall HB. Diagnosis and management of folate deficiency in low birthweight infants. Arch. Dis. Child. 1979; 54: 271-7.

63 Ehrenkranz RA. Iron, folic acid, and vitamin B12. In: Tsang RC, Lucas A, Uauy R, et al., eds. Nutritional Needs of the Preterm Infant: Scientific Basis and Practical Guidelines. Baltimore: Williams and Williams, 1993; 177-94.

64 Fleming AF. The aetiology of severe anaemia in pregnancy in Ndola, Zambia. Ann. Trop. Med. Parasitol. 1989; 83: 3749.

65 Batu AT, Toe T, Pe H, Nyunt KK. A prophylactic trial of iron and folic acid supplements in pregnant Burmese women. Isr. J. Med. Sci. 1976; 12: 1410-17.

66 Srisupandit S, Pootrakul P, Areekul S, et al. A prophylactic supplementation of iron and folate in pregnancy. Southeast Asian J. Trop. Med. Public Health 1983; 14: 317-23.

67 Charoenlarp P, Dhanamitta S, Kaewvichit R, et al. A WHO collaborative study on iron supplementation in Burma and Thailand. Am. J. Clin. Nutr. 1988; 47: 280-97.

68 Basu RN, Sood SK, Ramachandran K, Mathur M, Ramalingaswami V. Etiopathogenesis of nutritional anemia in pregnancy: a therapeutic approach. Am.J. Clin. Nutr. 1973; 26: $591-4$.

69 Sood SK, Ramachandran K, Mathur M, et al. WHO sponsored collaborative studies on nutritional anaemia in India: 1 . The effects of supplemental oral iron administration to pregnant women. Q. J. Med. 1975; 44: 241-58.

70 Iyengar L, Rajalakshmi K. Effect of folic acid supplement on birth weights of infants. Am.J. Obstet. Gynaecol. 1975; 122: 332-6.

71 Iyengar L, Apte SV. Prophylaxis of anemia of pregnancy. Am. J. Clin. Nutr. 1970; 23: 725-30.

72 Osifo B. The effect of folic acid and iron in the prevention of nutritional anaemias in pregnancy in Nigeria. Br. J. Nutr. 1970; 24: 689-94.

73 Jackson RT, Latham MC. Anemia of pregnancy in Liberia, West Africa: a therapeutic trial. Am. J. Clin. Nutr. 1982; 35: 710-14.

74 Fleming AF, Martin JD, Hahnel R, Westlake AJ. Effects of iron and folic acid antenatal supplements on maternal haematology and fetal wellbeing. Med.J. Aust. 1974; 2: 429-36.

75 Colman N, Larsen JV, Barker M, Barker EA, Green R, Metz J. Prevention of folate deficiency by food fortification. III. Effect in pregnant subjects of varying amounts of added folic acid. Am. J. Clin. Nutr. 1975; 28: 465-70.

76 Fleming AF, Ghatoura GBS, Harrison KA, Briggs ND, Dunn DT. The prevention of anaemia in pregnancy in primigravidae in the guinea savanna of Nigeria. Ann. Trop. Med. Parasitol. 1986; 80: 211-33.

77 Mackey AD, Picciano MF. Maternal folate status during extended lactation and the effect of supplemental folic acid. Am. J. Clin. Nutr. 1999; 69: 285-92.

78 Tee ES, Kandiah M, Awin N, et al. School-administered weekly iron-folate supplements improve hemoglobin and ferritin concentrations in Malaysian adolescent girls. Am.J. Clin. Nutr. 1999; 69: 1249-56.

79 Areekul S, Subcharoen A, Cheeramakara C, Srisukawat K, Limsuwan S. Studies on the effect of folic acid supplement on folate and vitamin B12 status in children. Southeast Asian J. Trop. Med. Public Health 1980; 11: 81-6.
80 Hoffbrand AV. Folate deficiency in premature infants. Arch Dis. Child. 1970; 45: 441-4.

81 Kendall AC, Jones EE, Wilson CID, Shinton NK, Elwood PC. Folic acid in low birthweight infants. Arch. Dis. Child. 1974 49: 736-8.

82 Roberts PMM, Arrowsmith DE, Lloyd AVC, Monk-Jones ME. Effect of folic acid treatment on premature infants. Arch. Dis. Child. 1972; 47: 631-4.

83 Stevens D, Burman D, Strelling MK, Morris A. Folic acid supplementation in low birth weight infants. Pediatrics 1979; 64: 333-5.

84 Worthington-White DA, Behnke M, Gross S. Premature infants require additional folate and vitamin B-12 to reduce the severity of the anemia of prematurity. Am.J. Clin. Nutr 1994; 60: 930-5.

85 Herbert V. Vitamin B12. In: Olsen RE, Broquist HP, Chichester CO, et al., eds Nutrition Reviews' Present Knowledge in Nutrition, 5th edn. Washington, DC: The Nutrition Foundation, 1984; 347-64.

86 Herbert V. Vitamin B12. In: Brown ML, ed. Present Knowledge in Nutrition. 6th edn. Washington, DC: International Life Sciences Institute/Nutrition Foundation, 1990; $170-8$.

87 Antony AC. Megaloblastic anemias. In: Hoffman R, Benz EJ, Shattil SJ, et al., eds. Hematology: Basic Principles and Practice. New York: Churchill Livingstone, 1991; 392-422.

88 Allen LH, Backstrand JR, Chavez A, Pelto GH. Functional Implications of Malnutrition. Mexico Project Final Report. Storrs, CT: University of Connecticut, 1992.

89 Allen LH. Vitamin B12 metabolism and status during pregnancy, lactation and infancy. In: Allen LH, Lonnerdal B, eds. Nutrient Regulation During Pregnancy, Lactation, and Infant Growth. New York: Plenum Press, 1994; 17386.

90 Levy S, Rachmilewitz EZ, Izak G, Salomonowitz A Rachmilewitz M. A therapeutic trial in anemia of pregnancy. Isr. J. Med. Sci. 1968; 4: 218-22.

91 Lane M, Alfrey P. The anemia of human riboflavin deficiency. Blood 1965; 25: 432-42.

92 Alfrey CP, Lane M. The effect of riboflavin deficiency on erythropoiesis. Semin. Hematol. 1970; 7: 49-54.

93 Bates CJ. Human riboflavin requirements and metabolic consequences of deficiency in man and animals. World Rev. Nutr. Diet. 1987; 50: 215-65.

94 Sirivech S, Driskell J, Frieden E. NADH-FMN oxidoreductase activity and iron content of organs from riboflavin and iron-deficient rats. J. Nutr. 1977; 107: 739-45.

95 Ulvik RJ. Ferritin iron as a substrate for synthesis of protoheme in intact rat liver mitochondria. FEBS Lett. 1981; 132: $281-4$

96 Perry GM, Anderson BB, Dodd N. The effect of riboflavin on red-cell vitamin B6 metabolism and globin synthesis. Biomedicine 1980; 33: 36-8.

97 Fairweather-Tait SJ, Powers HJ, Minski MJ, Whitehead J, Downes R. Riboflavin deficiency and iron absorption in adult Gambian men. Ann. Nutr. Metab. 1992; 36: 34-40.

98 Powers HJ. Riboflavin-iron interactions with particular emphasis on the gastrointestinal tract. Proc. Nutr. Soc. 1995; 54: 509-17.

99 Decker K, Dotis B, Glatzle D, Hinselmann M. Riboflavin status and anaemia in pregnant women. Nutr. Metab. 1977 21 (Suppl. 1): 17-19.

100 Powers HJ, Bates CJ, Lamb WH. Haematological response to supplements of iron and riboflavin to pregnant and lactating women in rural Gambia. Hum. Nutr. Clin. Nutr. 1985; 39C: $117-29$

101 Buzina R, Jusic M, Milanovic N, Sapunar J, Brubacher G. The effects of riboflavin administration on iron metabolism parameters in a school-going population. Int. J. Vitam Nutr. Res. 1979; 49: 136-43. 
102 Charoenlarp P, Pholpothi T, Chatpunyaporn P, Schelp FP. Effect of riboflavin on the hematologic changes in iron supplementation of schoolchildren. Southeast Asian J. Trop. Med. Public Health 1980; 11: 97-103.

103 Powers HJ, Bates CJ, Prentice AM, Lamb WH, Jepson M, Bowman $\mathrm{H}$. The relative effectiveness of iron and iron with riboflavin in correcting a microcytic anaemia in men and children in rural Gambia. Hum. Nutr. Clin. Nutr. 1983; 37C: $413-25$.

104 Suboticanec K, Stavljenic A, Schalch W, Buzina R. Effects of pyridoxine and riboflavin supplementation on physical fitness in young adolescents. Int. J. Vitam. Nutr. Res. 1990; 60: $81-8$.

105 Ajayi OA, Okike OC, Yusuf Y. Haematological response to supplements of riboflavin and ascorbic acid in Nigerian young adults. Eur. J. Haematol. 1990; 44: 209-12.

106 Oski FA. Anemia due to other nutritional deficiencies. In: Williams WJ, Beutler E, eds. Hematology. New York: McGraw-Hill, 1995; 511-15.

107 Bothwell TH, Bradlow BA, Jacobs P, et al. Iron metabolism in scurvy with special reference to erythropoiesis. $\mathrm{Br} . J$. Haematol. 1964; 10: 50-8.

108 Lynch SR, Cook JD. Interaction of vitamin C and iron. Ann. NY Acad. Sci. 1980; 355: 32-44.

109 Hallberg L, Brune M, Rossander-Hulthen L. Is there a physiological role of vitamin $\mathrm{C}$ in iron absorption? Ann. NY Acad. Sci. 1987; 498: 324-32.

110 Clark NG, Sheard NF, Kelleher JF. Treatment of irondeficiency anemia complicated by scurvy and folic acid deficiency. Nutr. Rev. 1992; 50: 134-7.

111 Cook JD, Monsen ER. Vitamin C, the common cold, and iron absorption. Am. J. Clin. Nutr. 1977; 30: 235-41.

112 Stokes PL, Melikian V, Leeming RL, Portman-Graham H, Blair JA, Cooke WT. Folate metabolism in scurvy. Am. J. Clin. Nutr. 1975; 28: 126-9.

113 Chow CK. Nutritional influence on cellular antioxidant defense systems. Am. J. Clin. Nutr. 1979; 32: 1066.

114 Hodges RE, Baker EM, Hood J, Sauberlich HE, March SC. Experimental scurvy in man. Am. J. Clin. Nutr. 1969; 22: $535-48$.

115 Hodges RE, Hood J, Canham JE, Sauberlich HE, Baker EM. Clinical manifestations of ascorbic acid deficiency in man. Am.J. Clin. Nutr. 1971; 24: 432-43.

116 Sauberlich HE. Ascorbic acid. In: Brown ML, ed. Present Knowledge in Nutrition, 6th edn. Washington, DC: International Life Sciences Institute/Nutrition Foundation, 1990; 132-41.

117 Garry PJ, Vanderjagt DJ, Hunt WC. Ascorbic acid intakes and plasma levels in healthy elderly. Ann. NY Acad. Sci. 1987; 498: 90-9.

118 National Research Council (NRC). Recommended Dietary Allowances. Washington, DC: National Academy Press, 1989.

119 Seshadri S, Shah A, Bhade S. Haematologic response of anaemic preschool children to ascorbic acid supplementation. Hum. Nutr. Appl. Nutr. 1985; 39: 151-4.

120 Mao X, Yao G. Effect of vitamin C supplementation on iron deficiency anemia in Chinese children. Biomed. Environ. Sci. 1992; 5: 125-9.

121 Angeles IT, Schultink WJ, Matulessi P, Gross R, Sastroamidjojo S. Decreased rate of stunting among anemic Indonesian preschool children through iron supplementation. Am. J. Clin. Nutr. 1993; 58: 339-42.

122 Suboticanec-Buzina K, Buzina R, Brubacher G, Sapunar J, Christeller S. Vitamin C status and physical working capacity in adolescents. Int. J. Vitam. Nutr. Res. 1984; 54: $55-60$.

123 Ajayi OA, Nnaji UR. Effect of ascorbic acid supplementation on haematological response and ascorbic acid status of young female adults. Ann. Nutr. Metab. 1990; 34: 32-6.
124 Hunt JR, Mullen LM, Lykken GI, Gallagher SK, Nielsen FH Ascorbic acid: effect on ongoing iron absorption and status in iron-depleted young women. Am. J. Clin. Nutr. 1990; 51 649-55.

125 Garcia OP, Diaz M, Rosado JL, Allen LH. Community trial of the efficacy of lime juice for improving iron status of iron deficient Mexican women. FASEB J. 1998; 12: A647 (abstract).

126 Kuizon MD, Platon TP, Ancheta LP, Angeles JC, Nunez CB, Macapinlac MP. Iron supplementation studies among pregnant women. Southeast Asian J. Trop. Med. Public Health 1979; 10: 520-7.

127 Sharma DC, Mathur R. Correction of anemia and iron deficiency in vegetarians by administration of ascorbic acid. Indian J. Physiol. Pharmacol. 1995; 39: 403-6.

128 Pekiner B, Nebioglu S. Effect of vitamin C on copper and iron status in men and guinea pigs. J. Nutr. Sci. Vitaminol. 1994; 40: 401-10.

129 Farrell PM, Roberts RJ. Vitamin E. In: Shils ME, Olson JA, Shike M, eds. Modern Nutrition in Health and Disease. Philadelphia: Lea and Febiger, 1994; 326-41.

130 Dinning JS, Day PL. Vitamin E deficiency in the monkey. I. Muscular dystrophy, hematologic changes and the excretion of urinary nitrogenous constituents. J. Exp. Med. 1957; 105: 395.

131 Marvin HN, Dinning JS, Day PL. Erythrocyte survival in vitamins E-deficient monkeys. Proc. Soc. Exp. Biol. Med. 1960; 105: 473-5.

132 Porter FS, Fitch CD, Dinning JS. Vitamin E deficiency in the monkey. IV. Further studies of the anemia with emphasis on bone marrow morphology. Blood 1962; 20: 471

133 Marvin HN. Erythrocyte survival of rats deficient in vitamin E on vitamin $\mathrm{B}_{6} . J$. Nutr. 1963; 80: 185-90.

134 Chou AC, Broun GO, Fitch CD. Abnormalities of iron metabolism and erythropoiesis in vitamin E-deficient rabbits. Blood 1978; 52: 187-95.

135 Horwitt MK, Century B, Zeman AA. Erythrocyte survival time and reticulocyte levels after tocopherol depletion in man. Am. J. Clin. Nutr. 1963; 12: 99-106.

136 Ehrenkranz RA. Vitamin E and the neonate. Am. J. Dis Child. 1980; 134: 1157-66.

137 Oski FA, Barness LA. Vitamin E deficiency: a previously unrecognized cause of hemolytic anemia in the premature infant. J. Pediatr. 1967; 70: 211-20.

138 Ritchie JH, Fish MB, McMasters V, Grossman M. Edema and hemolytic anemia in premature infants. N. Engl. J. Med. 1968; 279: 1185-90.

139 Lo SS, Frank D, Hitzig WH. Vitamin E and haemolytic anaemia in premature infants. Arch. Dis. Child. 1973; 48: $360-5$.

140 Williams ML, Shott RJ, O'Neal PL, Oski FA. Role of dietary iron and fat on vitamin E deficiency anemia of infancy. $N$ Engl. J. Med. 1975; 292: 887-90.

141 Gross SJ, Landaw SA, Oski FA. Vitamin E and neonatal hemolysis. Pediatrics 1977; 59: 995-7.

142 Melhorn DK, Gross S. Vitamin E-dependent anemia in the premature infant. I. Effects of large doses of medicinal iron. J. Pediatr. 1971; 79: 569-80.

143 Gross S, Melhorn DK. Vitamin E-dependent anemia in the premature infant. J. Pediatr. 1974; 85: 753-9.

144 Fermanian J, Salmon D, Olive G, Zambrowski S, Rossier A, Caldera R. Double blind study of vitamin E compared to placebo in the prevention of anemia in the low birth weight infant during the 7 th week of life: therapeutic study [in French]. Nouv. Rev. Fr. Hematol. Blood Cells 1976; 16: 245-54.

145 Blanchette V, Doyle J, Schmidt B, Zipursky A. Hematology. In: Avery GB, Fletcher MA, MacDonald MG, eds. Neonatology: Pathophysiology and Management of the Newborn. Philadelphia: JB Lipincott, 1994; 952-99.

146 Blanchette V, Bell E, Nahmias C, Garnett S, Milner R, 
Zipursky A. A randomized control trial of vitamin E therapy in the prevention of anemia in low birth weight (LBW) infants. Pediatr. Res. 1980; 14: 591.

147 Zipursky A. Vitamin E deficiency anemia in newborn infants. Clin. Perinatol. 1984; 11: 393-402.

148 Zipursky A, Brown EJ, Watts J, et al. Oral vitamin E supplementation for the prevention of anemia in premature infants: a controlled trial. Pediatrics 1987; 79: 61-8.

149 Conway SP, Rawson I, Dear PRF, Shires SE, Kelleher J. The early anaemia of the premature infant: is there a place for vitamin E supplementation? Br. J. Nutr. 1986; 56: 105-14.

150 Ferlin MLS, Chuan LS, Jorge SM, Vannucchi H. Early anemia of prematurity. Nutr. Res. 1998; 18: 1161-73.

151 Majaj AS. Vitamin E-responsive megaloblastic anemia in infants with protein-calorie malnutrition. Am. J. Clin. Nutr. 1963; 12: 374-9.

152 Whitaker JA, Fort EG, Vimokesant S, Dinning JS. Hematologic response to vitamin $\mathrm{E}$ in the anemia associated with proteincalorie malnutrition. Am. J. Clin. Nutr. 1967; 20: 783-9.

153 Asfour RY, Firzli S. Hematologic studies in undernourished children with low serum vitamin E levels. Am.J. Clin. Nutr. 1965; 17: 158-63.

154 Baker SJ, Pereira SM, Begum A. Failure of vitamin E therapy in the treatment of anemia of protein-calorie malnutrition. Blood 1968; 32: 717-25.

155 Kulapongs P. The effect of vitamin $\mathrm{E}$ on the anemia of protein-calorie malnutrition in northern Thai children. In: Olsen RE, ed. Protein-Calorie Malnutrition. New York: Academic Press, 1975; 263-8.

156 Neufeld EJ, Mandel H, Raz T, et al. Localization of the gene for thiamine-responsive megaloblastic anemia syndrome, on the long arm of chromosome 1, by homozygosity mapping. Am. J. Hum. Genet. 1997; 61: 1335-41.

157 Handler P, Featherston WP. The biochemical defect in nicotinic acid deficiency. J. Biol. Chem. 1943; 151: 395.

158 Spivak JL, Jackson DL. Pellagra: an analysis of 18 patients and a review of the literature. Johns Hopkins Med. J. 1977; 140: 295-309.

159 Wintrobe MM, Follis RH Jr, Alcayaga R, Paulson M, Humphreys S. Pantothenic acid deficiency in swine. Bull. Johns Hopkins Hosp. 1943; 73: 313.

160 Richert DA, Schulman MP. Vitamin interrelationships in heme synthesis. Am. J. Clin. Nutr. 1959; 7: 416-25.

161 McCurdy PR. Is there an anemia responsive to pantothenic acid? J. Am. Geriatr. Soc. 1973; 21: 88-91.

162 Ofori-Nkansah N, Weissenfels I, Pribilla W. Vitamin B6 deficiency anemia [in German]. Schweiz. Med. Wochenschr. 1975; 105: 1319-24.

163 Meier PJ, Giger U, Brandli O, Fehr J. Acquired, vitamin B6responsive, primary sideroblastic anemia, an enzyme deficiency in heme synthesis [in German]. Schweiz. Med. Wochenschr. 1981; 111: 1533-5.

164 Reinken L, Kurz R. Activity studies of an iron-vitamin $\mathrm{B}_{6}$ preparation for euteral treatment of iron deficiency anemia [in German]. Int. J. Vitam. Nutr. Res. 1975; 44: 41118.

165 Natta CL, Reynolds RD. Apparent vitamin B6 deficiency in sickle cell anemia. Am. J. Clin. Nutr. 1984; 40: 235-9.

166 Bradfield RB, Jensen MV, Gonzales L, Garrayar C. Effect of low-level iron and vitamin supplementation on a tropical anemia. Am. J. Clin. Nutr. 1968; 21: 57-67.

167 Reinken L, Kurz R. The treatment of anaemia due to irondeficiency with iron combined with vitamins [in German]. Klin. Padiatr. 1978; 190: 163-7.

168 Tell'mann Akh, Saava ME, Aasvee KE. Effects of prophylactic vitamin administration to Tallin's schoolchildren on their health and physical development [in Russian]. Vopr. Pitan. 1992; May-June: 36-40.

169 Buzina R, Grgic Z, Jusic M, Sapunar J, Milanovic N, Brubacher G. Nutritional status and physical working capacity. Hum. Nutr. Clin. Nutr. 1982; 36C: 429-38.

170 Das BK, Bal MS, Tripathi AM, Singla PN, Agarwal DK, Agarwal KN. Evaluation of frequency and dose of iron and other hematinics - an alternative strategy for anemia prophylaxis in rural preschoolers. Indian J. Pediatr. 1984; 21 933-8.

171 Powers HJ, Bates CJ, Lamb WH, Singh J, Gelman W, Webb E. Effects of a multivitamin and iron supplement on running performance in Gambian children. Hum. Nutr. Clin. Nutr. 1985; 39: 427-37.

172 Liu DS, Bates CJ, Yin TA, Wang XB, Lu CQ. Nutritional efficacy of a fortified weaning rusk in a rural area near Beijing. Am. J. Clin. Nutr. 1993; 57: 506-11.

173 Van Stuijvenberg ME, Kvalsvig JD, Faber M, Kruger M, Kenoyer DG, Benade AJ. Effect of iron-, iodine-, and betacarotene-fortified biscuits on the micronutrient status of primary school children: a randomized controlled trial. Am. J. Clin. Nutr. 1999; 69: 497-503.

174 Thu BD, Schultink W, Dillon D, Gross R, Leswara ND, Khoi HH. Effect of daily and weekly micronutrient supplementation on micronutrient deficiencies and growth in young Vietnamese children. Am. J. Clin. Nutr. 1999; 69: 80-6.

175 Angeles-Agdeppa I, Schultink W, Sastroamidjojo S, Gross R, Karyadi D. Weekly micronutrient supplementation to build iron stores in female Indonesian adolescents. Am. J. Clin. Nutr. 1997; 66: 177-83.

176 Scholl TO, Hediger ML, Bendich A, Schall JI, Smith WK, Krueger PM. Use of multivitamin/mineral prenatal supplements: influence on the outcome of pregnancy. Am.J. Epidemiol. 1997; 146: 134-41. 